\title{
Macro/Microtesting and Damage and Degradation of Sandstones under Dry-Wet Cycles
}

\author{
Xinrong Liu, ${ }^{1,2}$ Zijuan Wang, ${ }^{1,2}$ Yan Fu, ${ }^{3}$ Wen Yuan, ${ }^{1,2}$ and Luli Miao ${ }^{1,2}$ \\ ${ }^{1}$ College of Civil Engineering, Chongqing University, Chongqing 400045, China \\ ${ }^{2}$ Key Laboratory of New Technology for Construction of Cities in Mountain Area (Chongqing University), \\ Ministry of Education, Chongqing 400045, China \\ ${ }^{3}$ College of Construction Management and Real Estate, Chongqing University, Chongqing 400045, China
}

Correspondence should be addressed to Zijuan Wang; 346484339@qq.com

Received 20 January 2016; Accepted 8 March 2016

Academic Editor: Luigi Nicolais

Copyright (C) 2016 Xinrong Liu et al. This is an open access article distributed under the Creative Commons Attribution License, which permits unrestricted use, distribution, and reproduction in any medium, provided the original work is properly cited.

In terms of the degradation of mechanical parameters of rock mass in the hydrofluctuation belt of a reservoir bank slope arising from rainfall and the reservoir level fluctuation, the moderately weathered sandstone in a side slope of the Three Gorges Reservoir Region is selected as a research object to carry out "drying-saturation-drying" tests for disks with two thicknesses $(h=25 \mathrm{~mm}$, $h=50 \mathrm{~mm}$ ) in different cycles; a spiral CT machine, an ultrasonic velocity meter, and a light Schmidt hammer are utilzed to conduct nondestructive testing on dry-wet cycles; through the Brazilian splitting test, the uniaxial tensile strength of "dry" and "saturated" sandstones under different dry-wet cycles is obtained. The research shows that, with the increase of the dry-wet circles $(n)$, the longitudinal wave velocity and the rebound strength of sandstones are linearly decreased with $n$; the uniaxial tensile strength of sandstones and the mean CT number of cross sections are logarithmically decreased with $n$; the fitting equation of macro/micromechanical parameters and dry-wet cycles $(n)$ of sandstones is raised, which is provided as a reference basis for the weathering process of sandstones under dry-wet cycles.

\section{Introduction}

The softening of sandstones by water absorption is a strength and stiffness reduction phenomenon caused by physical action [1-3]. For the sandstone in a natural side slope, the sandstone is not in a purely soaking state. Affected by rainfall or reservoir water circulation, it will be in a "water absorption-air drying" state. The repeated water absorption/loss process of sandstones is a complicated physical and chemical process [4-6]. For the hydrofluctuation belt of the Three Gorges Reservoir Region, the water level difference is up to $30 \mathrm{~m}$, which has a huge impact on the stability of the reservoir slope [7-13]. In recent years, some progress has been made regarding the research of the influence of dry-wet cycles on soil strength [14-17], but there are few researches with respect to the lithology degradation of sandstones under the drywet cycles of reservoir water, and the influence research of sandstones is still in the trial test stage. Jeng et al. $[18,19]$,
Hale and Shakoor [20], and Reviron et al. [21] carried out discussions on the mechanical property of sandstones under dry-wet cycles, but different test results were obtained, and the degradation mechanism of sandstones caused by dry-wet cycles remained unclear.

In recent years, such methods as CT scanning, ultrasonic velocity testing, and rebound method have gradually emerged to test the damage degree of sandstones. For the CT testing of sandstones, the microfailure mechanism of sandstones is researched through the observation on the microdamage changes of sandstone materials, and the macrodamage evolution equation of sandstone media and the constitutive relation thereof are established [22,23]. New damage will not be caused by ultrasonic testing, and ultrasonic velocity is one of the indexes for evaluating material damage. The rebound testing method is widely applied to the testing of concrete structure, which can be used to qualitatively determine the structure hardness and can be used as a strength 
basis of material. The testing of small-sized sandstone strength by the rebound method is not nondestructive testing, but quasi-nondestructive testing. Through testing and theoretical analyzing of the relation between strain rate and damage mechanism of rock materials, Eibl et al. [24-26] raised the dynamic constitutive model of sandstones. Pfeiffer et al. $[27,28]$ combined the kinetic equation of the system with the constraint equation thereof and raised the kinetic model of multipoint collision multi-rigid-body system. As the tensile strength of sandstone materials is far below the compressive strength thereof, the rock failure often starts with the tensile stress zone. Tensile fracture is one of the basic forms of rock failure, and the tensile strength of the rock is a control parameter for strength design and strength analysis of rock structure. The Brazilian disk splitting method is the most extensive testing method for determining the tensile strength of rocks so far [29-31]. Tavallali and Vervoort $[32,33]$ carried out the Brazilian splitting test on stratified sandstone, revealed the failure modes of stratified sandstone under different bedding angles, and obtained the distribution relation of sandstone strength with the different bedding angles.

The long-term strength and deformation changes of sandstones under dry-wet cycles and the geological hazard problem arising therefrom are both a severe and an unavoidable reality problem to be researched and solved [34]. Therefore, it is necessary to further carry out the research on the damage and degradation effect of sandstones under dry-wet cycles. In this paper, through the approximate simulation of drywet cycles in the "drying-saturation-drying" process in a laboratory, as well as the "ultrasonic-CT-rebound" integrated testing method and Brazilian splitting test, the change rule of sandstone strength and deformation caused by dry-wet cycles is researched, the test results are analyzed and concluded, and the change rule and damage evolution characteristics of macro/micromechanical parameters of sandstones under dry-wet cycles are obtained and provided as a reference for relevant engineering designs.

\section{Experimental}

2.1. Specimen Fabrication. In this test, the change rule of macro/microparameters (moisture content, rebound value, longitudinal wave velocity, CT number, and tensile strength) of sandstones under "immersion-air drying" is researched in a repeated way. The moderately weathered sandstone at the hydrofluctuation belt of a side slope in Three Gorges Reservoir Region is selected to conduct a laboratory test. Sandstone processing is conducted on the ZS-100 vertical core drilling machine in the Geotechnical Engineering Laboratory of Chongqing University, with the diameter error $\leq 0.1 \mathrm{~mm}$ and the nonparallelism of end face $\leq 0.02 \mathrm{~mm}$. The $\mathrm{ZC} 4$ brick test resiliometer is used to screen the processed specimens, and the specimens with a large difference in rebound values are eliminated.

To obtain the uniaxial tensile strength of sandstones under dry-wet cycles through the Brazilian disk splitting test, the sandstones with the diameter $D=50 \mathrm{~mm}$ and the heights (h) are, respectively, $25 \mathrm{~mm}$ and $50 \mathrm{~mm}$. The specimens of each size are divided into two types. One type is used as the "saturated" specimens under dry-wet cycles, while the other is used as the "dry" specimens under dry-wet cycles. Each type of specimens is divided into 6 groups. Each group is composed of 3 specimens, with one group reserved for standby application. The remaining groups are applied to the dry-wet cycle test with the dry-wet circle $n=0,1,3,6$, and 10 in the distilled water environment.

2.2. Test Procedure. First, the specimen is placed in an oven for $24 \mathrm{~h}$ drying at a temperature of $105^{\circ} \mathrm{C}$. Then, it is soaked for $24 \mathrm{~h}$ by vacuum saturation method. This process is a dry-wet cycle process. An intelligent concrete vacuum water saturation device is adopted for saturation. The specimen is placed in water and undergoes continuous pumping for $4 \mathrm{~h}$ at $-80 \mathrm{kpa}$. Afterwards, the water saturation device automatically pumps water until the specimen is submerged. After $20 \mathrm{~h}$ standing, the vacuum saturation process is completed. The mass, longitudinal wave velocity, and rebound value of upper and lower bottoms of the specimen under "dry" and "saturated" conditions in each dry-wet circle are measured. For the longitudinal wave test of the sandstone specimen, the ultrasonic pulse penetration method is adopted. The test instrument is the versatile nondestructive testing acquisition and analysis system (Freedom Data PC) manufactured by U.S. OLSON Company. For the rebound value test of the specimen, the test scheme of the upper and lower bottoms of the specimen hammered by the ZC4 brick test resiliometer is adopted. Spiral CT scanning is adopted on the two sizes of "saturated" sandstones in different dry-wet cycles. The test instrument is Toshiba Aquilion 16 Spiral CT Scanner. The scanning method is that one layer is scanned every $1 \mathrm{~mm}$.

In the Brazilian disk splitting test adopting curved molds, the uniaxial tensile strength of sandstones under "saturated" and "dry" conditions with different dry-wet cycles is obtained. The test instrument is Shimadzu AGI-250 kN electric servo testing machine of Chongqing University. The displacement loading mode is adopted, with a loading speed of $0.1 \mathrm{~mm} / \mathrm{min}$. In the test process, the computer automatically collects axial load and displacement data until the sandstone specimen is damaged. The test equipment is shown in Figure 1. The initial physical parameters of the specimen are shown in Table 1.

\section{Results and Discussion}

3.1. Research on the Change Rule of Water Absorption of Sandstones under Dry-Wet Cycles. The water absorption of sandstones is one of its important water-physical properties and is determined according to such factors as the number and size of opening pores, the arrangement method of mineral particles, the situation of whether the sandstone is easily affected with damp, and the situation of air excluded in pores. The smaller the water absorption is, the harder and more compact the sandstone surface will be, with better engineering properties. The mass of sandstones under "saturated" and "dry" conditions after each dry-wet cycle test is measured. Through mass conversion, the saturated water absorption of the sandstone under each dry-wet cycle 
TABLE 1: Physical parameters of the sandstone.

\begin{tabular}{lccccc}
\hline $\begin{array}{l}\text { Height of specimen } \\
(\mathrm{mm})\end{array}$ & $\begin{array}{c}\text { Quality } \\
(\mathrm{g})\end{array}$ & $\begin{array}{c}\text { Natural moisture content } \\
(\%)\end{array}$ & $\begin{array}{c}\text { Saturated moisture content } \\
(\%)\end{array}$ & $\begin{array}{c}\text { Initial density } \\
\left(\mathrm{g} / \mathrm{cm}^{3}\right)\end{array}$ & $\begin{array}{c}\text { Dry density } \\
\left(\mathrm{g} / \mathrm{cm}^{3}\right)\end{array}$ \\
\hline 25 & 119.95 & 1.58 & 2.41 & 2.43 & 2.4 \\
50 & 241.61 & 1.94 & 2.69 & 2.52 \\
\hline
\end{tabular}

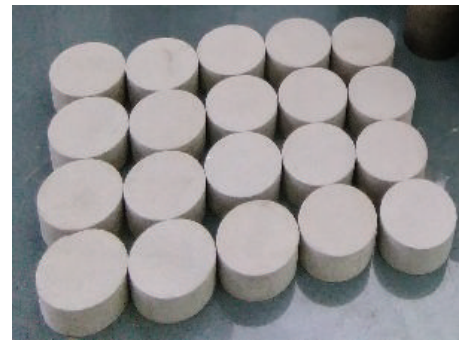

(a) Initial state

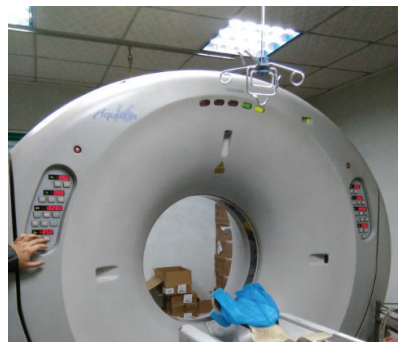

(e) CT Scanner

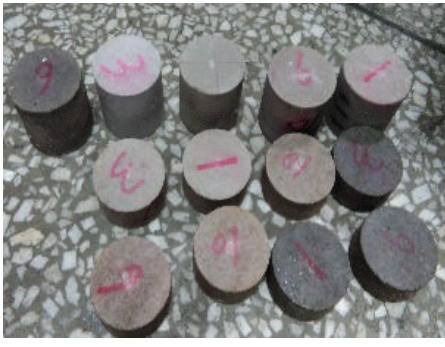

(b) Dry-wet cycles

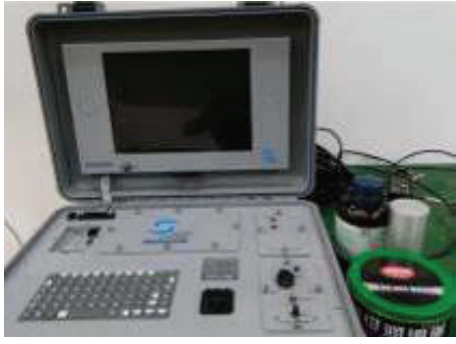

(f) Freedom Data PC

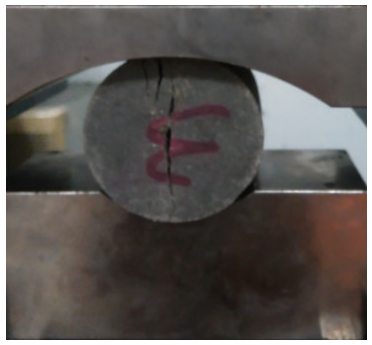

(c) Curved molds

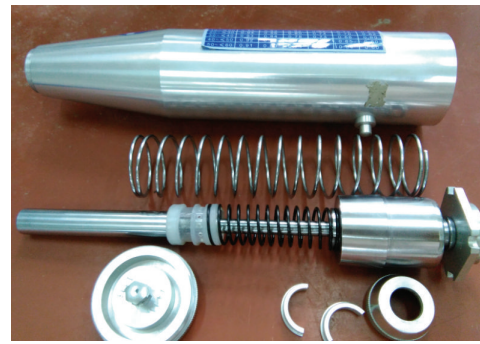

(g) ZC4

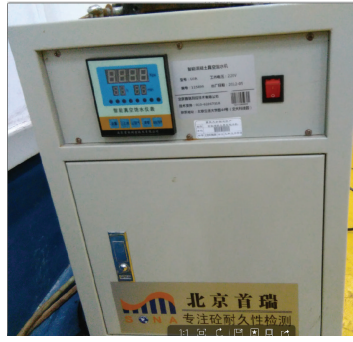

(d) Saturation device

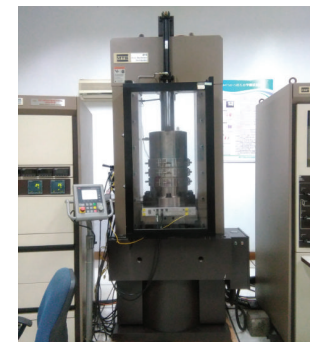

(h) AGI- $250 \mathrm{kN}$

FIGURE 1: Some samples of the sandstones and testing equipment.

TABLE 2: Results of water absorption test of the sandstones.

\begin{tabular}{lccc}
\hline $\begin{array}{l}\text { Dry-wet } \\
\text { cycles }\end{array}$ & $\begin{array}{c}\text { Water } \\
\text { absorption } \\
n\end{array}$ & $\begin{array}{c}\text { Water } \\
\text { absorption } \\
\omega(n)_{25}(\%)\end{array}$ & $\begin{array}{c}\left(\omega_{50}-\omega_{25}\right) / \omega_{25} \times \\
100 \% \\
50\end{array}$ \\
\hline 0 & 1.59 & 1.94 & 21.85 \\
1 & 2.41 & 2.69 & 11.82 \\
2 & 2.88 & 2.84 & -1.49 \\
3 & 3.00 & 3.07 & 2.21 \\
4 & 3.14 & 3.26 & 4.04 \\
5 & 3.24 & 3.52 & 8.48 \\
6 & 3.40 & 3.64 & 6.93 \\
7 & 3.42 & 3.87 & 13.08 \\
8 & 3.46 & 3.96 & 14.48 \\
9 & 3.51 & 4.23 & 20.52 \\
10 & 3.67 & 4.44 & 20.71 \\
\hline
\end{tabular}

is obtained, and the test results are shown in Table 2. The table shows that the selected sandstone has large water absorption, wherein water has a significant influence on it, and the engineering properties are poor; the water absorption of the sandstone is increased with the increase of the dry-wet cycles; the water absorption effect of the sandstone with

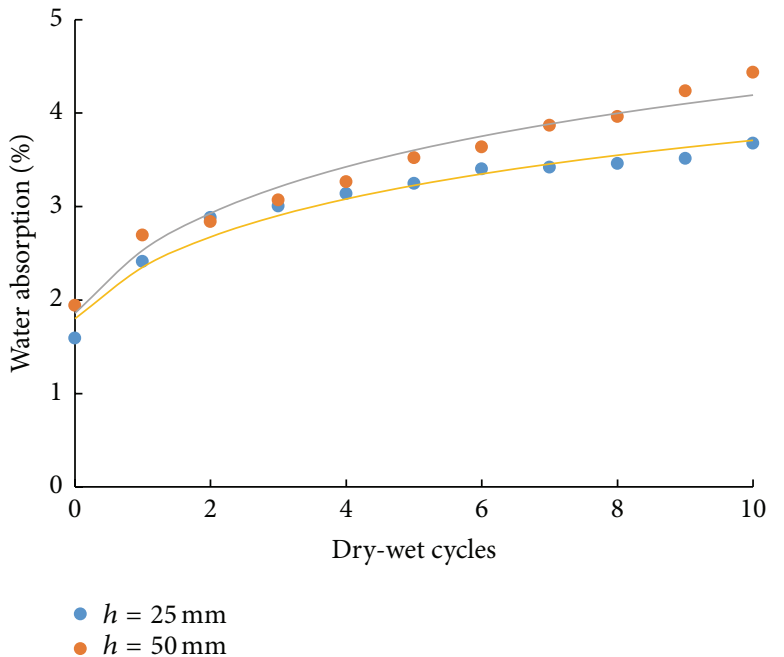

FIGURE 2: Relationship between water absorption of sandstones and dry-wet cycles.

the thickness $h=50 \mathrm{~mm}$ is slightly better than that with the thickness $h=25 \mathrm{~mm}$. The influence rule of dry-wet cycles on the water absorption of sandstones is sought, as shown in Figure 2. With the increase of the dry-wet cycle $n$, a continuous variation occurs in water absorption of 
TABLE 3: CT images and 3D reconstruction of sandstone under different dry-wet cycles.

(a)

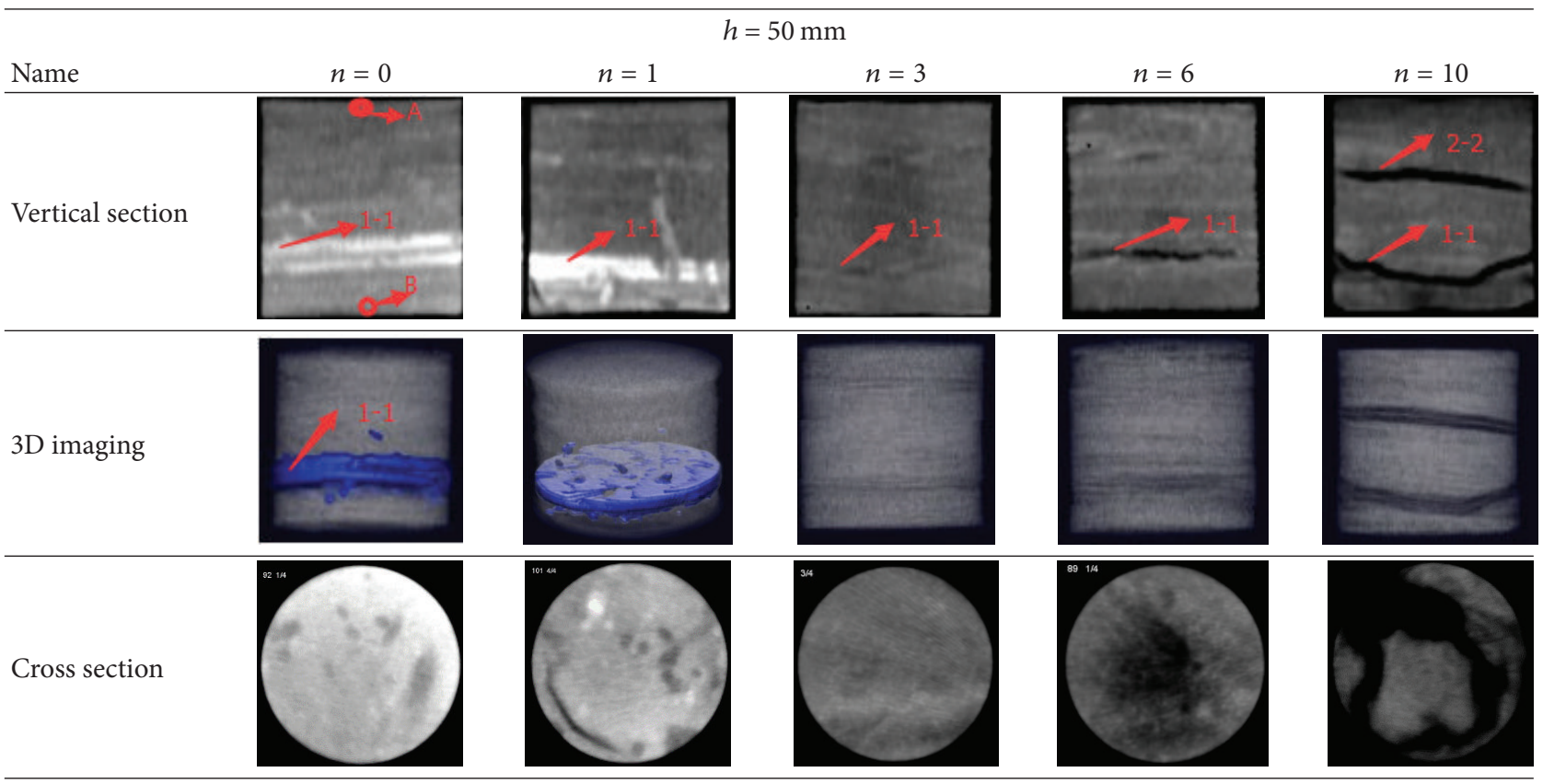

(b)

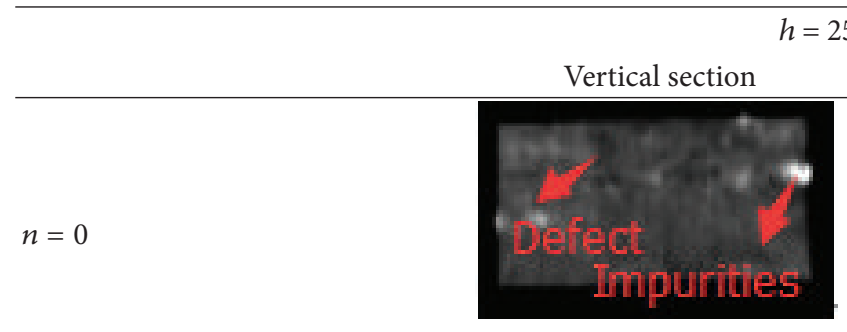

(A)

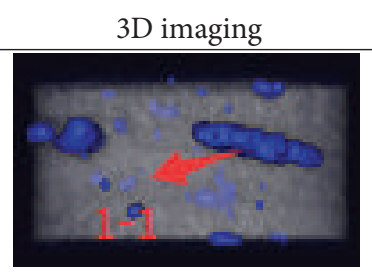

(B)
Cross section

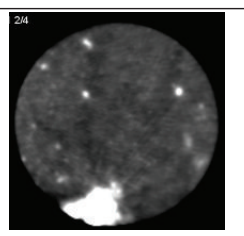

(C) the sandstone. Then, the test results are fitted to obtain the expression of two sizes of sandstones continuously varying with the increase of dry-wet cycles

$$
\begin{aligned}
& \omega(n)_{50}=1.858+0.973 \ln (n+1), \\
& \omega(n)_{25}=1.802+0.795 \ln (n+1),
\end{aligned}
$$

wherein $\omega(n)_{50}$ and $\omega(n)_{25}$, respectively, represent the water absorption of sandstone specimens with the disk thickness $h=50 \mathrm{~mm}$ and $h=25 \mathrm{~mm}$ under dry-wet cycles $(n)$.

The related coefficients of the two are, respectively, 0.9623 and 0.9604, showing a good fitting effect. As shown in Figure 1, under the alternation of drying and wetting, the water absorption of sandstones is logarithmically increased with the increase of cycle number; in the initial stage of drywet cycles, the water absorption of sandstones of two sizes shows a big increasing rate, but the increasing rate is gradually lowered in the later stage.

3.2. Research on the Change Rule of Microcharacteristics of Sandstones under Dry-Wet Cycles. The application of CT technology to material damage defect detection mainly includes qualitative analysis and quantitative analysis. In this paper, the microstructure change of sandstones under drywet cycles is mainly studied. CT whole-section scanning is conducted on two sizes of "saturated" specimens under 0 , $1,3,6$, and 10 dry-wet cycles (five dry-wet cycle schemes), respectively, and the scanning is carried out for 10 times in total. With the increase of dry-wet cycles, the sandstone density is decreased and the porosity is increased, which may cause the increase of moisture content, the decrease of mean CT number, and the increase of variance. As shown in Table 3, the second line depicts the CT scanning image of the vertical section of the specimen with $h=50 \mathrm{~mm}$ under different dry-wet cycles, wherein the black and white contrast in the CT image shows the density distribution of the tested object, including such defects as internal pores and microcracks of the object. As seen from the figure, with the increase of dry-wet cycles, the high density area of specimens is gradually decreased while the defect area thereof is gradually expanded; when the dry-wet cycles $n \geq$ 6 , microcracks start to appear in the specimens. The third line in the table depicts the $3 \mathrm{D}$ reconstruction of 252 images scanned under the "saturated" condition of specimens by 


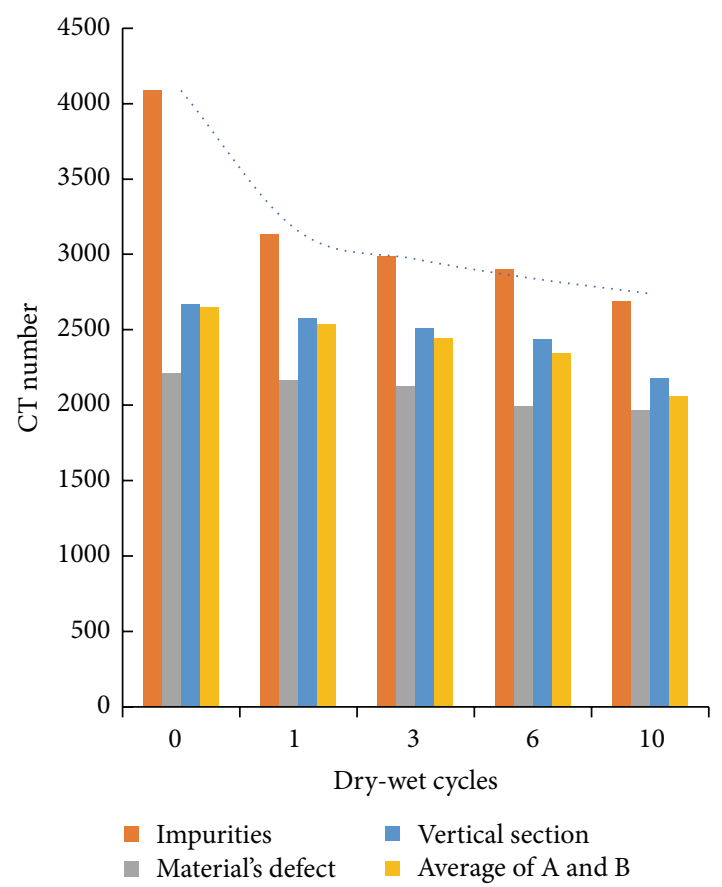

(a) $h=25 \mathrm{~mm}$

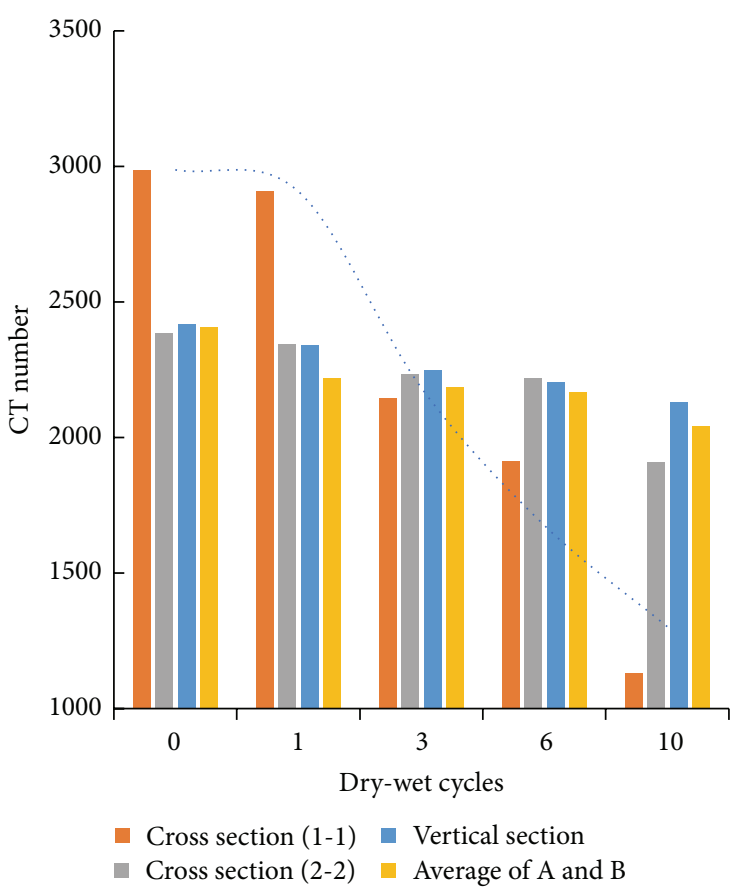

(b) $h=50 \mathrm{~mm}$

FIGURE 3: Relationship between CT number of sandstones and dry-wet cycles.

the utilization of maximum intensity projection (MIP). MIP means that the maximum density of each wiring harness is projected to reflect the density difference of tissues. As shown in the figure, the specimens are anisotropic. The CT value of the blue part in the figure is relatively large, and the sandstones are provided with significant stratification. The fourth line in the table depicts the CT scanning image of the special section, cross section 1-1 of sandstones in the second line varying with the dry-wet cycles $(n)$. As shown in the figure, physical and chemical weathering occurs in sandstones under the water-rock interaction; softening appears at the special section of the specimen, resulting in the decrease of density. With the accumulation of drywet cycles, the corrosion degree is increased, which finally causes the transverse microcracks on the specimen. When the transverse microcracks are coalesced, the specimen loses its strength. When the specimen $h=25 \mathrm{~mm}$, its CT scanning images are similar. In the sixth line of Table 3 , Figure (A) is the vertical section image of the specimen with $h=25 \mathrm{~mm}$; Figure $(\mathrm{B})$ is the $3 \mathrm{D}$ reconstruction image; Figure $(\mathrm{C})$ is the CT scanning image of cross section 1-1 at the impurity in Figures (A) and (B). As shown in the figure, the impurities and microdefects contained in small-sized specimens are random, with a high anisotropic index.

CT scanning is defined to be computer tomography, which provides a new means for the nondestructive testing of sandstones. Its fundamental principle is shown as follows: $\mathrm{X}$-ray is utilized to penetrate through an object section, and the attenuation information of $\mathrm{X}$-ray penetrating through the section of a layer is collected. The CT image of the sandstone is a digital image in nature. The value of each pixel point is the CT number which is directly proportional to the corresponding sandstone density. The bright color on the CT image represents the high density area of the sandstone, while the dark color represents the low density area thereof. The CT numbers of pure water, ice, and air are, respectively, defined as 0 (HU), -100 (HU), and -1000 (HU). Then, the CT number $H$ of an object is defined as

$$
H=\frac{\mu-\mu_{w}}{\mu_{w}} * 1000,
$$

wherein $\mu$ is the absorption coefficient of the tested object and $\mu_{w}$ is the absorption coefficient of water.

With reference to Table 3, when $h=25 \mathrm{~mm}$, the mean CT numbers of the vertical section, cross section 1-1 with impurities, cross section 2-2 with defects, and the area hammered by the resiliometer of the sandstone under dry-wet cycles are shown in Figure 3(a). A downtrend is shown in the internal mean CT numbers of the sandstone with the increase of the dry-wet cycles. The mean CT numbers of the area hammered by the resiliometer are decreased by $18.33 \%, 34.18 \%$, $11.14 \%$, and $22.12 \%$, respectively. When $h=50 \mathrm{~mm}$, mean CT numbers of the vertical section, cross section 1-1, cross section 2-2, and the area hammered by the resiliometer of the sandstone under dry-wet cycles are shown in Figure 3(b). As seen from the figure, with the increase of the dry-wet cycles, the mean CT number of the vertical section of the sandstone is gradually decreased and is finally decreased by $11.81 \%$; the mean CT number of the area hammered by the resiliometer is decreased by $15.13 \%$, which is larger than the decrease degree of the mean CT number of the vertical section. It shows that the testing method of small-sized sandstone hammered 
by the resiliometer pertains to quasi-nondestructive testing. The mean CT number of cross section 1-1 with microcrack coalescence is changed from 2986.10 to 1132.80 and decreased by $62.06 \%$; the mean CT number of section $2-2$ is decreased by $24.89 \%$.

In case the resolution of CT equipment is $m_{0}$, the damage variable is as follows:

$$
\begin{aligned}
& D(n)=\frac{1}{m_{0}^{2}}\left[1-\frac{\rho(n)}{\rho_{0}}\right], \\
& \rho(n)=\frac{1000+H_{n}}{1000+H_{0}} \rho_{0} .
\end{aligned}
$$

After (4) is substituted into (3), the following equation is obtained:

$$
D(n)=\frac{1}{m_{0}^{2}}\left[1-\frac{1000+H_{n}}{1000+H_{0}}\right] .
$$

When the image resolution $m_{0}=1$, the damage variable is as follows:

$$
D_{H}(n)=\frac{H_{0}-H_{n}}{1000+H_{0}},
$$

wherein $D_{H}(n)$ is the damage variable of the microparameter of the sandstone corresponding to dry-wet cycle $n ; H_{n}$ is the mean CT number of the special section of sandstone under dry-wet cycle $n ; H_{0}$ is the mean CT number of the corresponding section of sandstone under the initial state.

After the mean CT numbers of vertical section, cross section 1-1, and the area of upper and lower bottoms hammered by the resiliometer of two sizes $(h=25 \mathrm{~mm}, h=$ $50 \mathrm{~mm}$ ) of "saturated" sandstones under different dry-wet cycles are, respectively, substituted into (6), the damage variable of microcharacteristics of sandstones under dry-wet cycles represented by CT numbers is obtained. As shown in Figure 4, the microdamage variable defined as mean CT numbers is gradually increased with the increase of drywet cycles, wherein the damage variable of section $1-1>$ the damage variable of the area hammered by the resiliometer $>$ the overall damage variable of the vertical section. When $h=50 \mathrm{~mm}$ and $n \geq 6$, through-wall cracks appear in the specimen, and its corresponding microdamage variable is 0.269 ; that is, when damage variable $D(n) \geq 0.269$ represented by the CT number, it loses its bearing capacity.

As the variation in the mean CT number of the damaged cross section 1-1 under dry-wet cycles is defined as the microdamage parameter of material, then the following equation is obtained:

$$
D_{H}(n)=\frac{H_{0(1-1)}-H_{n(1-1)}}{1000+H_{0(1-1)}} .
$$

Through formula fitting, the following equation is obtained:

$$
D_{H}(n)=p \ln \left(n^{q}+1\right),
$$

wherein $p$ and $q$ are proportional constants, the specific values of which are shown in Table 4 . The related coefficients of the two are both larger than 0.951, showing a good fitting effect.
TABLE 4: Fitting coefficient of CT number of sandstones and dry-wet cycles.

\begin{tabular}{lccccc}
\hline $\begin{array}{l}\text { Height } \\
(\mathrm{mm})\end{array}$ & $H_{0(1-1)}$ & State & $P$ & $q$ & Related coefficient $/ R^{2}$ \\
\hline 25 & 4086.9 & Dry & 0.2641 & 0.232 & 0.992 \\
50 & 2986.1 & Dry & 0.0288 & 6.378 & 0.951 \\
\hline
\end{tabular}

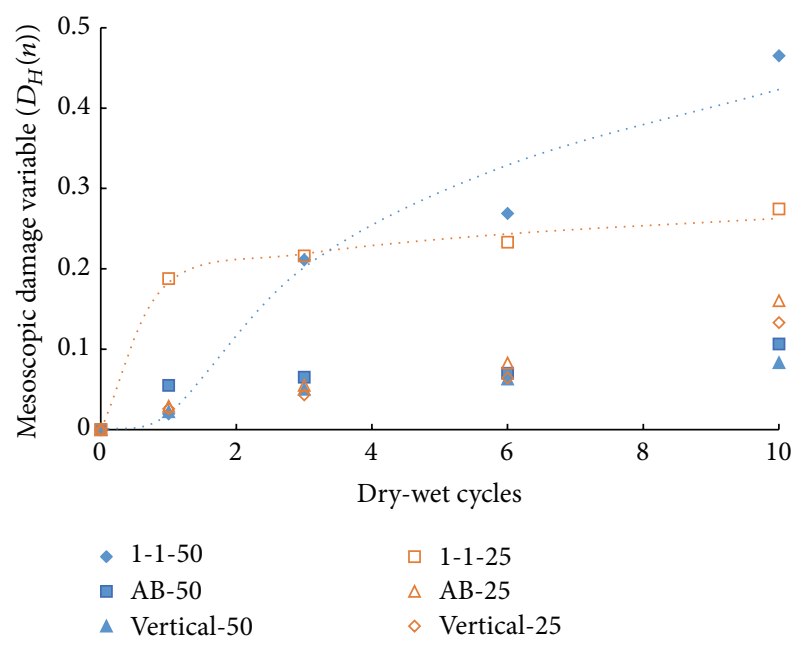

FIGURE 4: Relationship between mesoscopic damage variables of sandstones and dry-wet cycles.

\subsection{Research on the Change Rule of Longitudinal Wave Velocity} of Sandstones under Dry-Wet Cycles. When the vibration direction of mass is consistent with the propagation direction of wave, the wave is longitudinal wave. Due to the differences in minerals, cementation degree of minerals, and development degree of pores and microcracks of sandstones, the longitudinal wave velocity thereof is different as well. In addition, the difference in sizes and moisture contents of sandstones also produce different influence on the longitudinal wave velocity.

When the longitudinal wave velocity of sandstone is being measured, a proper amount of lubricating grease is adopted for coupling between the longitudinal wave transducer and the sandstone specimen. Prior to each test, a standard specimen is used for acoustic wave calibration to fix the time of the wave passing through the specimen as $24.6 \mu \mathrm{s}$; thus, the stability of the acoustic emission signal is guaranteed. The longitudinal waveform of the dried and saturated sandstone specimen and the time $t$ from the transmitting probe to the receiving probe are tested in proper order. The calculation formula of the longitudinal wave velocity is shown as follows:

$$
v_{p}=\frac{h}{t}
$$

wherein $v_{p}$ is the longitudinal wave velocity $(\mathrm{m} / \mathrm{s}) ; h$ is the specimen height $(\mathrm{m}) ; t$ is the time (s) of the longitudinal wave velocity from the transmitting probe to the receiving probe. 


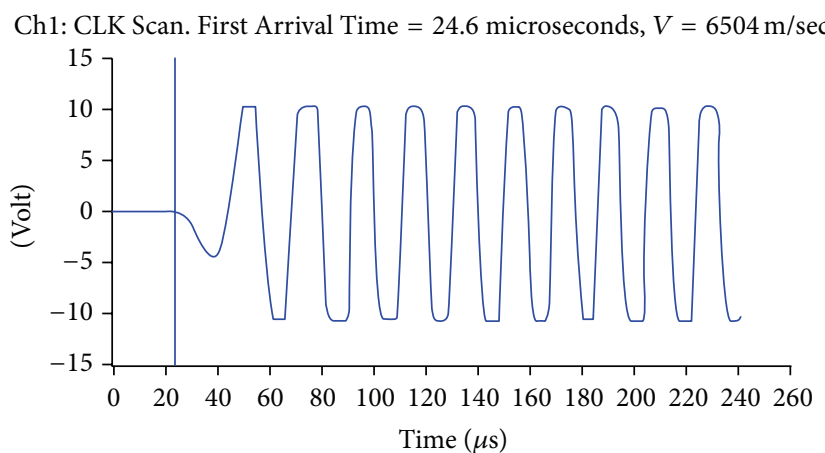

(a) Dry

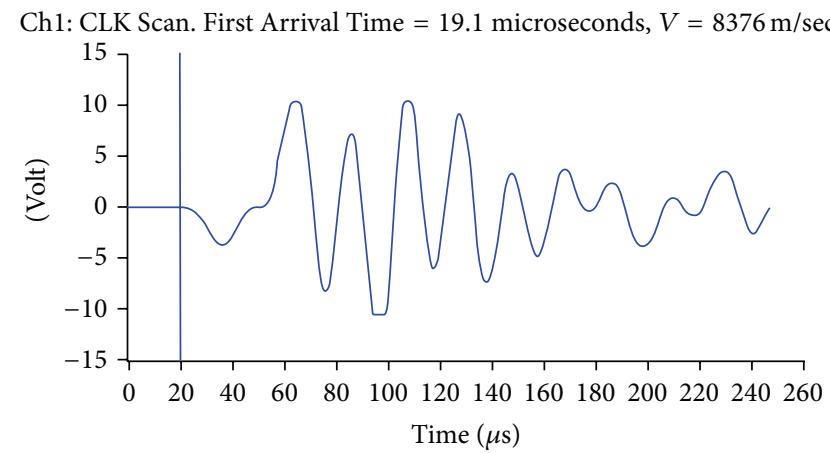

(b) Saturated

FIGURE 5: Waveform of longitudinal wave to sandstone in different water content.

The typical longitudinal waveform curves of sandstones under dry and saturated conditions are shown in Figure 5, and its peak frequency $=50781$. Figure $5(a)$ is waveform curve of the specimen with $h=50 \mathrm{~mm}$ under the "dry" condition and is a continuous wave. The waveform of sandstones under the "dry" condition under different dry-wet cycles is similar to it, but the time of the wave passing through the specimen is different. Figure $5(\mathrm{~b})$ is the waveform curve of the specimen with $h=50 \mathrm{~mm}$ under the "saturated" condition. As the "saturated" specimen not only constitutes the mineral component of sandstones, but also is under the action of water, the waveform is changed from the continuous curve under the "dry" condition to an amplitude-varying curve. With the increase of dry-wet cycles, the saturated water content of specimen is increased, the internal microdefects are gradually enlarged, and the specimen nonuniformity is increased, resulting in increased instability of curve fluctuation. For the same specimen, the time $t$ of the longitudinal wave of the saturated sandstone from the transmitting probe to the receiving probe is smaller than that of the dry sandstone. As shown in (9), the longitudinal wave velocity of the "saturated" sandstone is larger than that of the "dry" sandstone.

The thicknesses of the specimens selected in this test are quite small ( $h=50 \mathrm{~mm}, h=25 \mathrm{~mm}$ ), and the coupling agent has to be applied before the measuring of longitudinal wave velocity each time. Therefore, a deviation appears in the applied thickness due to human factors. The uniformity of coupling agent applied on the specimen under the "saturated" condition is lowered, causing a more obvious deviation. As seen from the test results, the longitudinal wave velocity of the sandstone under the "saturated" condition fluctuates within 2673.07 14695.91. The data discreteness is quite large; they are not valid data. The longitudinal wave velocities of two sizes of dry sandstones under different dry-wet cycles are shown in the primary axis of Figure 6. With the increase of the dry-wet cycle $n$, the longitudinal wave velocity of the sandstone is gradually lowered. Through data fitting, the following equation can be obtained:

$$
V_{P}(n)=V_{P 0}-g n,
$$

TABLE 5: Fitting coefficient of longitudinal wave velocity of sandstones and dry-wet cycles.

\begin{tabular}{lcccc}
\hline Height $(\mathrm{mm})$ & $V_{P 0}$ & State & $g$ & Related coefficient $/ R^{2}$ \\
\hline 25 & 5530.1 & Dry & 362.16 & 0.9111 \\
50 & 3499.9 & Dry & 274.26 & 0.9874 \\
\hline
\end{tabular}

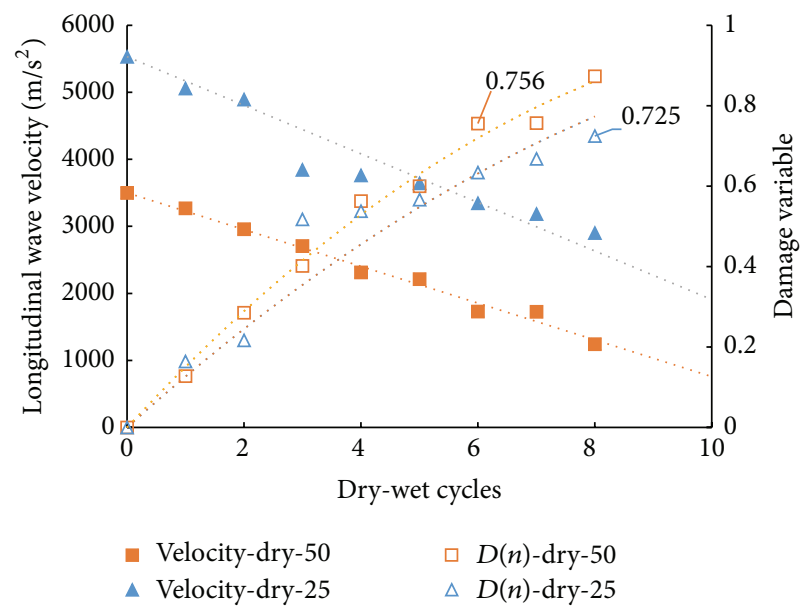

FIGURE 6: Relationship between longitudinal wave velocity and damage variable of sandstones and dry-wet cycles.

where $V_{P}(n)$ is the longitudinal wave velocity of the corresponding sandstone under dry-wet cycle $n ; V_{P 0}$ is longitudinal wave velocity of the sandstone under the initial state; $g$ is a proportional constant. The specific values are shown in Table 5 .

As seen from the related coefficient $R^{2}$ in Table 5, the fitting effect between the longitudinal wave velocity of the dry sandstone and the dry-wet cycles is good. The $g$ value reflects the degree of the longitudinal wave velocity of the dry sandstone decreasing with $n$. The larger the $g$ value is, the higher the decrease intensity will be. 
As seen from the basic motion equation of elastic mechanics, the longitudinal wave velocity is shown as follows:

$$
\begin{gathered}
V_{P}=\sqrt{\frac{E(1-\mu)}{\rho(1+\mu)(1-2 \mu)},} \\
E=\frac{\rho(1+\mu)(1-2 \mu)}{(1-\mu)} V_{P}^{2} .
\end{gathered}
$$

According to Lemaitre strain equivalence hypothesis, the damage variable of sandstones under dry-wet cycles is defined as follows:

$$
D(n)=1-\frac{E_{0}}{E_{n}} .
$$

After (12) is substituted into (13), the damage variable of sandstones based on the longitudinal wave velocity is obtained:

$$
D_{p}(n)=1-\left(\frac{V_{P}(n)}{V_{P 0}}\right)^{2},
$$

where $V_{P}(n)$ is the longitudinal wave velocity $(\mathrm{m} / \mathrm{s})$ of the sandstone after dry-wet cycles $n$ and $V_{P 0}$ is longitudinal wave velocity of the sandstone under the initial state.

After (10) is substituted into (14), the following equation is obtained:

$$
D_{P}(n)=-\left(\frac{g n}{V_{P 0}}\right)^{2}+\frac{2 g n}{V_{P 0}} .
$$

The longitudinal wave velocity values of the dry sandstone under different dry-wet cycles are substituted into (15) to obtain the relationship between the damage variable of the sandstone and the dry-wet cycle number, as shown in the secondary coordinate of Figure 6. As seen from the figure, with the increase of the dry-wet cycles $n$, the damage variable of the specimen with $h=50 \mathrm{~mm}$ is larger than that with $h=25 \mathrm{~mm}$. The damage variable value ranges within $0 \sim 1$ and is related to the parabola of the dry-wet cycle number. When $h=50 \mathrm{~mm}$ and $n \geq 6$, through-wall cracks appear in the specimen, and its corresponding damage variable is 0.756 ; that is, when the damage variable $D(n) \geq 0.756$ expressed by longitudinal wave velocity, it loses its bearing capacity.

\subsection{Research on the Change Rule of Rebound \\ Strength of Sandstones under Dry-Wet Cycles}

3.4.1. Basic Principle of Rebound Testing. The response of sandstone to impact load is divided into fluid mechanics, plasticity, and elasticity. If the impact load is strong, the sandstone may be handled as compressed fluid; if the stress generated by the impact load is below the yield point, the sandstone is in the elastic state. The impact load arising from the small-sized sandstone surface hammered by the resiliometer is between the two, and then the sandstone falls within the plasticity range. The testing of small-sized sandstone strength by the rebound method is not nondestructive testing, but quasi-nondestructive testing. The predication of sandstone strength by the rebound method is carried out through the relationship between the surface hardness and strength of sandstone. Its testing principle is as follows: a spring is utilized to drive a heavy hammer; through the upper and lower bottoms of the sandstone specimen hammered by the hammering rod, the rebound distance of the specimen is measured, and the rebound value (the ratio of the rebound length to the normal working length of the hammering rod) is regarded as the strength-related index.

When the recoiling hammer is driven to the potential energy $E$ at the initial state prior to the impact, the energy loss of the hammering rod is $\Delta E$. $\Delta E$ is related to the surface hardness of sandstone, while the surface hardness of sandstone is related to its compressive strength:

$$
\begin{aligned}
\Delta E & =\frac{1}{2} M V_{0}^{2}-\frac{1}{2} M V_{1}^{2}=\frac{1}{2} K L_{0}^{2}-\frac{1}{2} K L_{1}^{2}, \\
\Delta E & =\frac{1}{2} K L_{0}^{2}\left(1-\frac{L_{1}^{2}}{L_{0}^{2}}\right), \\
e_{1} & =\frac{V_{1}}{V_{0}} \\
e_{2} & =\frac{R}{100}=\sqrt{\frac{L_{1}^{2}}{L_{0}^{2}}}
\end{aligned}
$$

where $e_{1}$ is the coefficient of kinetic energy loss; $e_{2}$ is the coefficient of elastic potential energy loss; $V_{0}$ is the initial velocity of the sandstone surface hammered by the recoiling hammer; $V_{1}$ is the initial velocity of the rebound of the recoiling hammer; $L_{0}$ is the normal working length of the resiliometer; $L_{1}$ is the rebound height; $M$ is the mass of the recoiling hammer; $K$ is the elastic coefficient of the tension spring; $R$ is the rebound value.

3.4.2. Change Rule of Rebound Strength of Sandstones under Dry-Wet Cycles. The rebound strength testing of sandstone under "saturated" and "dry" conditions after each dry-wet cycle is carried out. The test results are shown in Figure 7. With the increase of dry-wet cycles, the rebound strength of sandstone is gradually decreased, showing a linear decline trend as a whole. The hardness of the sandstone under the "dry" condition is higher than that under the "saturated" condition, so the rebound strength of the sandstone under the "dry" condition is higher than that under the "saturated" condition. The rebound strength of the sandstone with the thickness $h=25 \mathrm{~mm}$ is higher than that with the thickness $h=25 \mathrm{~mm}$. For the sandstone with the thickness $h=$ $50 \mathrm{~mm}$, when $n=8$, its rebound strength under the saturated condition is lower than 10 , which exceeds the minimum testing range of the resiliometer. It can be considered that when $h=50 \mathrm{~mm}$ and $n \geq 8$, the rebound strength of the sandstone under the saturated condition is $R(n)=0$. The expression for the rebound strength of two sizes of sandstones under two conditions varying with the dry-wet cycles is in conformity with the following equation:

$$
R(n)=R_{0}-e n .
$$




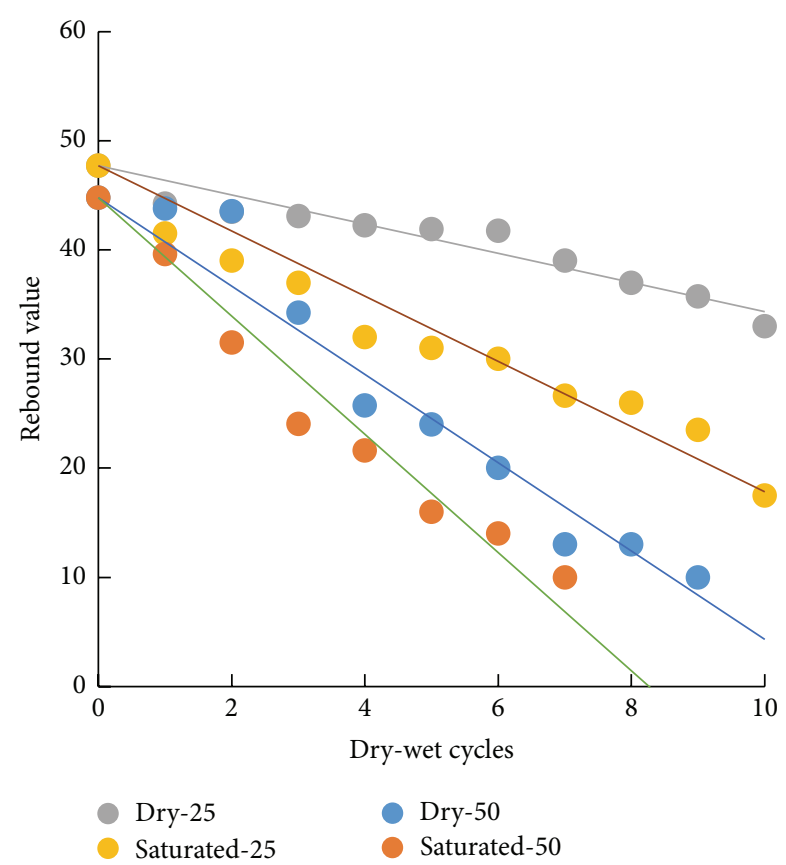

FIGURE 7: Relationship between rebound values of sandstones and dry-wet cycles.

TABLE 6: Fitting coefficient of rebound value of sandstones and drywet cycles.

\begin{tabular}{lcccc}
\hline $\begin{array}{l}\text { Height } \\
(\mathrm{mm})\end{array}$ & $R_{0}$ & State & $e$ & Related coefficient $/ R^{2}$ \\
\hline 25 & 47.75 & Dry & 1.34 & 0.919 \\
& & Saturated & 2.991 & 0.9332 \\
\hline 50 & \multirow{2}{*}{44.81} & Dry & 4.052 & 0.9504 \\
& & Saturated & 5.423 & 0.9596 \\
\hline
\end{tabular}

$R(n)$ is the rebound strength of the sandstone corresponding to the dry-wet cycle $n ; R_{0}$ is the rebound strength of the sandstone under the initial state; $e$ is a proportional constant; the specific values are shown in Table $3 ; n$ is the dry-wet cycle number.

As seen from the related coefficient $R^{2}$ of Table 6, the fitting effect between the rebound strength of sandstone and its dry-wet cycles is good. The $e$ value reflects the degree of the rebound strength of sandstone decreasing with $n$. The larger the $e$ value is, the higher the decrease intensity will be.

Through (10) and (17), the following equation can be obtained:

$$
V_{P}(n)=\frac{g}{e} R(n)-\left(\frac{g}{e} R_{0}-V_{P 0}\right) .
$$

As shown in (18), $e$ and $g$ of the same size of specimens under the same condition are constants. Thus, the longitudinal wave velocity of the sandstone under the dry condition is linearly related to its rebound strength. As shown in (14),

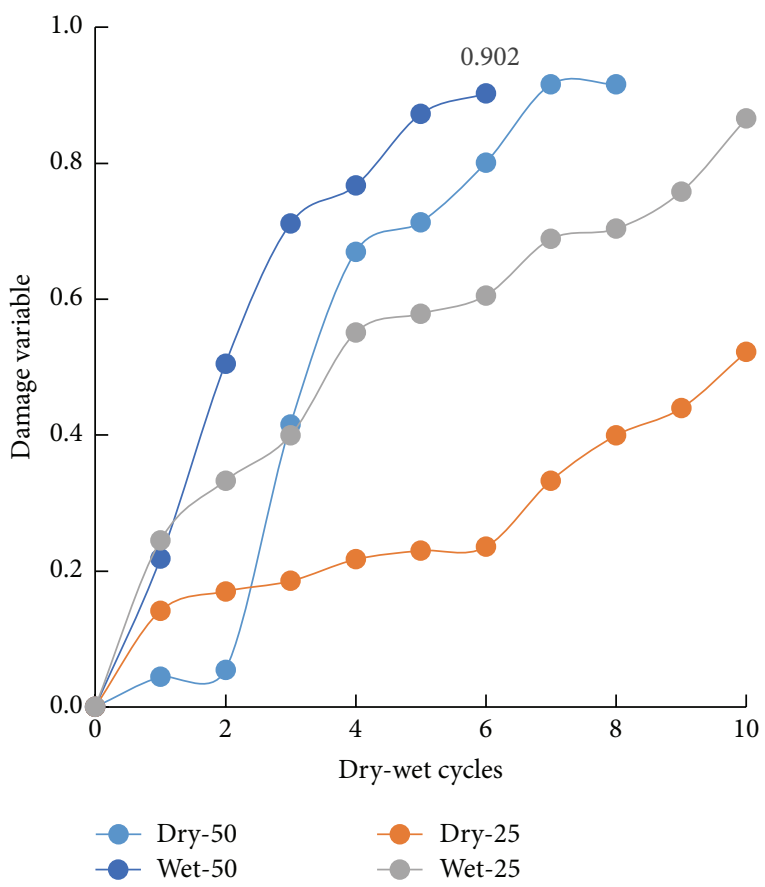

FIGURE 8: Relationship between damage variables of sandstones and dry-wet cycles.

the damage variable defined as the rebound strength of sandstone is as follows:

$$
D_{R}(n)=1-\left(\frac{R(n)}{R_{0}}\right)^{2} .
$$

After (18) is substituted into (19), the following equation is obtained:

$$
D_{R}(n)=-\left(\frac{e n}{R_{0}}\right)^{2}+\frac{2 e n}{R_{0}} .
$$

The rebound strength values of "saturated" and "dry" sandstones under different dry-wet cycles are substituted into (19) to obtain the relationship between the damage variable of sandstone and the dry-wet cycle number, as shown in Figure 8. As seen from the figure, with the increase of the dry-wet cycles, the damage variable of the specimen with $h=50 \mathrm{~mm}$ is larger than that with $h=25 \mathrm{~mm}$, and the damage variable value ranges within $0 \sim 1$. When $h=50 \mathrm{~mm}$ and $n \geq 6$, through-wall cracks appear in the specimen, and its corresponding damage variable is 0.902 ; that is, when the damage variable $D(n) \geq 0.902$ expressed by rebound strength, it loses its bearing capacity.

\section{Research on the Splitting Test and Damage Rule of Sandstone under Dry-Wet Cycles}

4.1. Load-Displacement Curve. The load-displacement curve of Brazilian disks of two thickness sizes under different drywet cycles and moisture contents is shown in Figure 9. In the figure, $n$ is the dry-wet cycle number and $h$ is the disk thickness. With the gradual increase of axial displacement, 


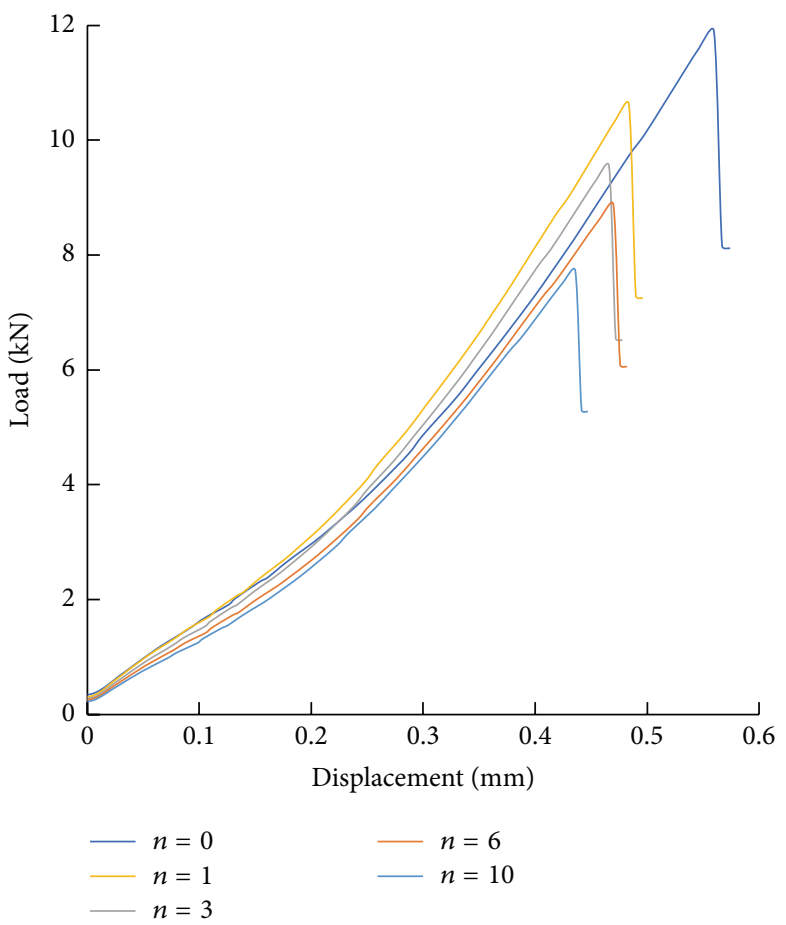

(a) $\operatorname{Dry}(h=25 \mathrm{~mm})$

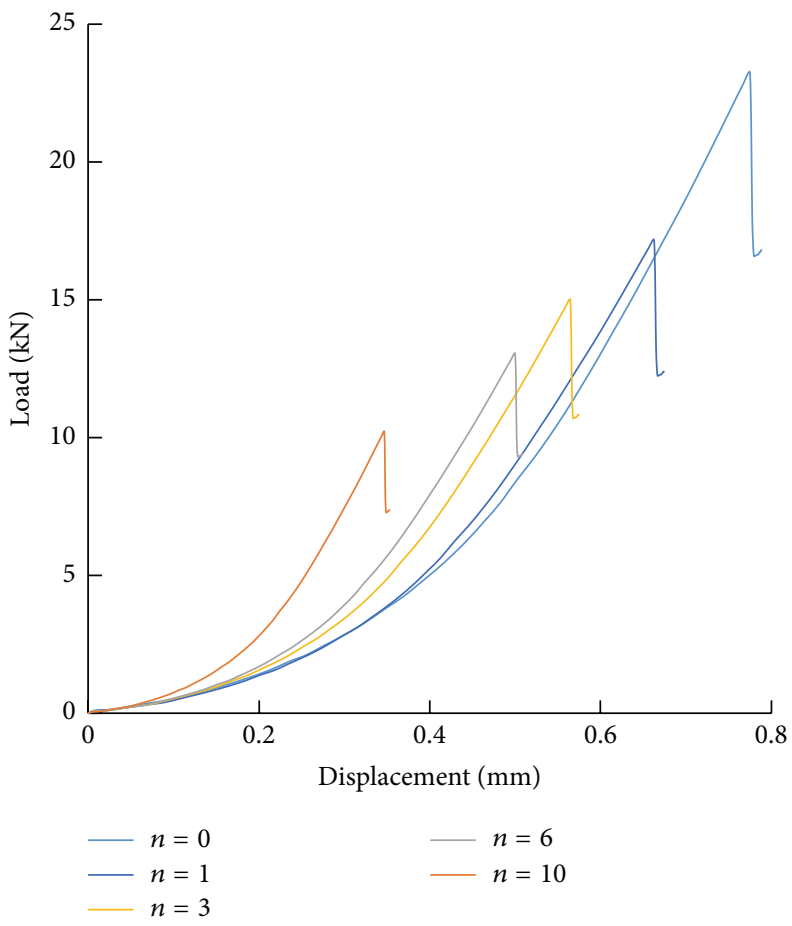

(c) $\operatorname{Dry}(h=50 \mathrm{~mm})$

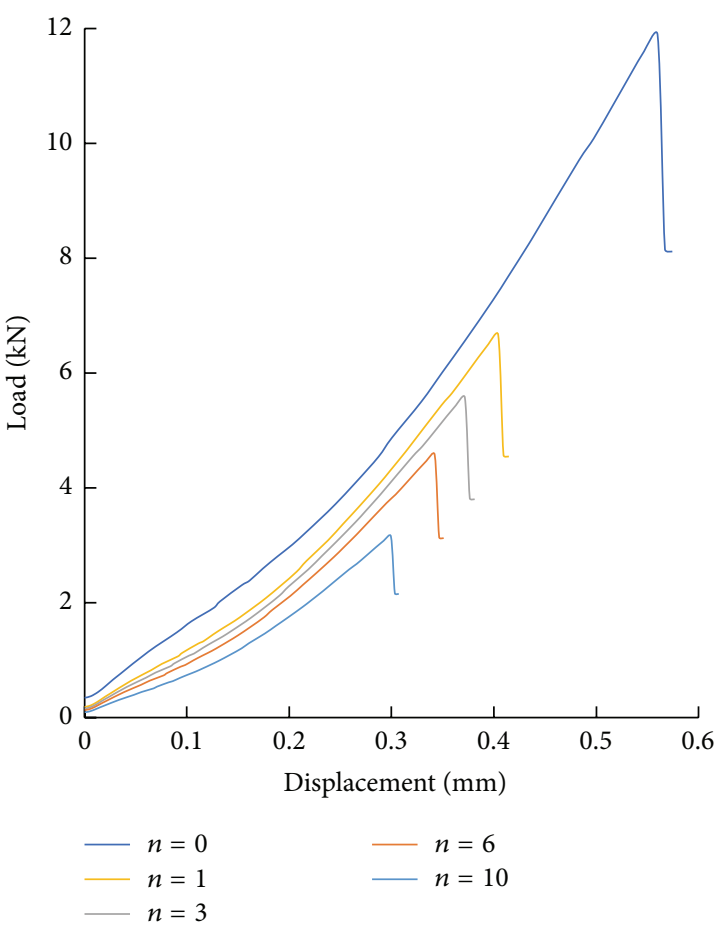

(b) Saturated $(h=25 \mathrm{~mm})$

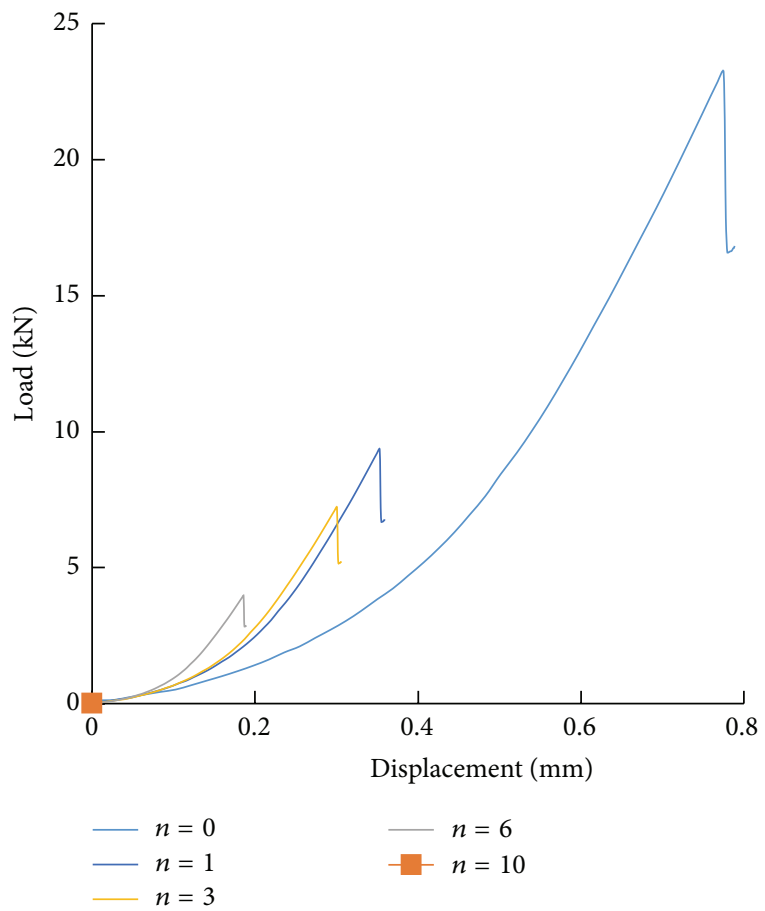

(d) Saturated $(h=50 \mathrm{~mm})$

Figure 9: The load-displacement curve of the specimen with different height under different dry-wet cycles.

as a whole, the load-displacement curve undergoes a development process of compaction-linear stage-postpeak fall; the curve is unobvious in the prepeak yield stage; it generally shows brittleness characteristics; after the axial load reaches the peak value, the disk almost loses its bearing capacity within a short period of time. Under combination (a), the slope variation range of the load-displacement curve in the elastic stage is within 12.11 14.51; under combination (b), the variation range is within 7.20 14.51; under combination (c), the variation range is within 19.22 22.26; under combination (d), the variation range is within 15.87 22.26; the deviations between the maximum and minimum values 


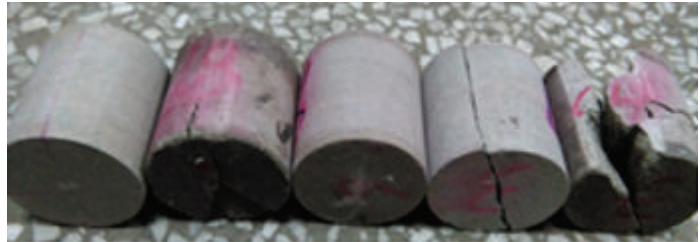

(a) $h=50 \mathrm{~mm}$

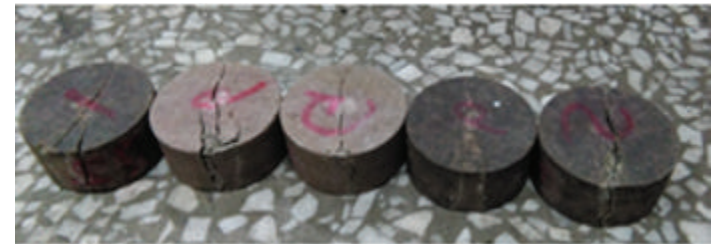

(b) $h=25 \mathrm{~mm}$

FIGURE 10: The damage form of sandstone after splitting test.

of the slopes under all combinations are $16.54 \%, 51.52 \%$, $13.66 \%$, and $28.71 \%$, respectively. As seen from these data, the evolution trend of the dry-wet cycles to the slope under the saturated condition is more obvious than that under the dry condition. For the sandstone under dry-wet cycles, its peak displacement is decreased, and its brittleness is increased. After the sandstone is dried, the decreased tensile strength under water-rock interaction is partly recovered, but it generally shows a decreasing trend.

4.2. Analysis on Failure Characteristics of the Disk under DryWet Cycles. The failure modes of sandstone under different dry-wet cycles, moisture contents, and disk thicknesses are shown in Figure 10. The primary cracks are all longitudinally arranged along the disk, and there is a certain difference in the number of secondary cracks, spreading direction, and so forth. With the increase of dry-wet cycles, the number of secondary cracks is gradually increased, basically developing in a symmetric way. The emergence and development of cracks are macromanifestation of the thermodynamics phenomenon, reflecting the aggregation and conversion of energy consumption. In the loading process, the load imposed by the upper end forms uniform linear load power on the disk. In case the outside dissipation is neglected, it can be considered that it is totally converted into the total energy absorbed by the disk. When the disk is loaded to $i$ step, the corresponding upper load and axial displacement are $P_{i}$ and $\Delta l_{i}$, respectively. At this moment, the total energy $K$ absorbed by the unit-thickness disk is shown as follows:

$$
K=\frac{\sum P_{i} \Delta l_{i}}{h}
$$

When the total displacement reaches the peak displacement, the total energy absorbed by the unit-thickness disk also reaches the maximum value $K_{0}$. The characteristic curve of $K_{0}$ varying with the dry-wet cycles is shown in Figure 11. As seen from the figure, the total energy absorbed by the unit-thickness disk is decreased with the increase of drywet cycles, and the decreasing degree of the energy absorbed by the disk with a thickness of $50 \mathrm{~mm}$ is the largest. The decreasing trend of the total energy absorbed by the unitthickness specimen under the saturated condition with the increase of dry-wet cycles is larger than that under the dry condition. When the dry-wet cycle number is 1 , the decreasing amplitudes of energy are $22.78 \%, 36.81 \%, 59.5 \%$, and $81.69 \%$, respectively. In the later stage, with the increase of dry-wet cycles, the decreasing trend becomes slow. Under
TABLE 7: Fitting coefficient of energy absorption of unit-thickness disk and dry-wet cycles.

\begin{tabular}{|c|c|c|c|c|c|}
\hline $\begin{array}{l}\text { Height } \\
(\mathrm{mm})\end{array}$ & $K_{0}$ & State & $f$ & $g$ & $\begin{array}{c}\text { Related } \\
\text { coefficient } / R^{2}\end{array}$ \\
\hline \multirow{2}{*}{25} & \multirow{2}{*}{0.305} & Dry & 0.3184 & 0.5311 & 0.9833 \\
\hline & & Saturated & 0.8432 & 0.2339 & 0.9979 \\
\hline \multirow{2}{*}{50} & \multirow{2}{*}{0.497} & Dry & 0.5136 & 0.5509 & 0.9937 \\
\hline & & Saturated & 1.1672 & 0.1303 & 0.9993 \\
\hline
\end{tabular}

different working conditions, the expression of the maximum energy $K_{0}$ absorbed in the unit-thickness disk splitting test of sandstone varying with the dry-wet cycles is in conformity with the following equation:

$$
K_{0}(n)=K_{0}(0)\left[1-f \ln \left(n^{g}+1\right)\right] .
$$

$K_{0}(n)$ is the maximum energy absorbed in the sandstone splitting test corresponding to dry-wet cycles $(n) ; K_{0}(0)$ is the maximum absorbed energy of sandstone under the initial state; $f$ and $g$ are proportional constants; the specific values are shown in Table 7. The related coefficients of the two are both larger than 0.9833 , showing a good fitting effect.

4.3. Change Rules of Uniaxial Tensile Strength and Damage of Sandstone under Dry-Wet Cycles. In research of the stress and strain of each anisotropic elastic body, the anisotropic elastic body is considered as a continuous medium. The relationship between stress and strain in the Brazilian splitting test is shown as follows:

$$
\left\{\begin{array}{c}
\varepsilon_{x} \\
\varepsilon_{y} \\
\gamma_{x y}
\end{array}\right\}=\left[\begin{array}{lll}
a_{11} & a_{12} & a_{16} \\
a_{12} & a_{22} & a_{26} \\
a_{16} & a_{26} & a_{66}
\end{array}\right]\left\{\begin{array}{c}
\sigma_{x} \\
\sigma_{y} \\
\tau_{x y}
\end{array}\right\} .
$$

The stress component is expressed as

$$
\begin{aligned}
\sigma_{x} & =\frac{P}{\pi D t} q_{x x}, \\
\sigma_{y} & =\frac{P}{\pi D t} q_{y y}, \\
\tau_{x y} & =\frac{P}{\pi D t} q_{x y} .
\end{aligned}
$$

$q_{x x}, q_{y y}$, and $q_{x y}$ are stress concentration factors and are, respectively, the function between independent elastic constants and bedding angle $\beta$. 


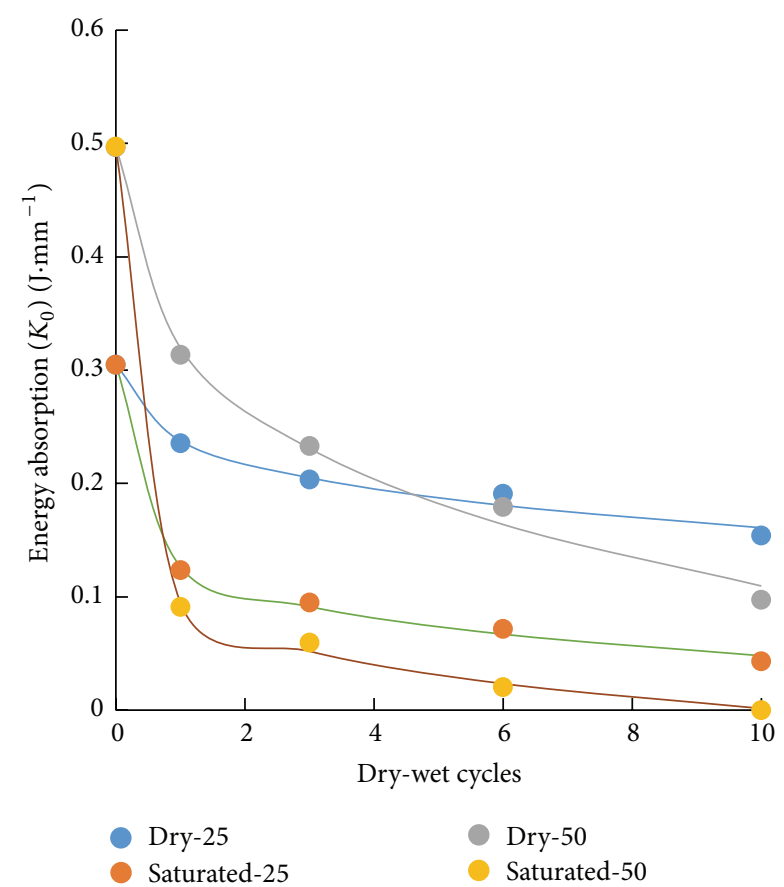

FIGURE 11: Relationship between energy absorption of unit-thickness disk and dry-wet cycles.

At the center point of the disk specimen, the tensile stress $\sigma_{x}=-2 P_{x} / \pi D h$, the compressive stress $\sigma_{y}=6 P_{t} /$ $\pi D h$, and the compressive strength of sandstone material is generally $8 \sim 10$ times of the tensile strength, so the specimen undergoes tensile failure rather than compression failure. In the static-load disk splitting test, the uniaxial tensile strength of sandstone is shown as follows:

$$
\sigma_{t}=-\frac{2 P_{t}}{\pi D h}
$$

$\sigma_{t}$ is the tensile strength of sandstone; $h$ is length (thickness) of the specimen; $D$ is diameter; $P_{t}$ is failure load.

The peak loads in the splitting test of two sizes $(h=$ $25 \mathrm{~mm}, h=50 \mathrm{~mm}$ ) of sandstones under different dry-wet cycles are substituted into (24), respectively, to obtain the uniaxial compressive strength of sandstones under different working conditions, as shown in Figure 12. As seen from the figure, with the increase of dry-wet cycles, the uniaxial compressive strength of sandstones is logarithmically decreased. The decreasing trend is fast in the initial stage and becomes slow in the later stage. Under the same working condition, the uniaxial tensile strength of the sandstone under the "dry" condition is larger than that under the "saturated" condition; the uniaxial tensile strength of the sandstone with a thickness of $25 \mathrm{~mm}$ is larger than that with a thickness of $50 \mathrm{~mm}$. The expression of the uniaxial tensile strength of sandstones varying with dry-wet cycles under different working conditions is in conformity with the following equation:

$$
\sigma_{t}(n)=\sigma_{t 0}\left[1-a \ln \left(n^{b}+1\right)\right]
$$

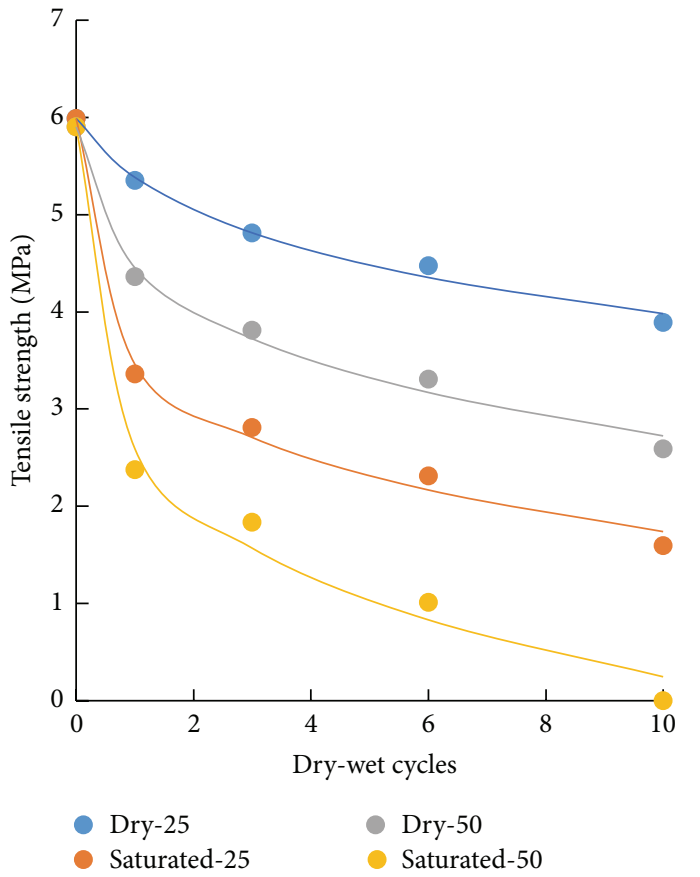

FIGURE 12: Relationship between tensile strength of sandstones and dry-wet cycles.

$\sigma_{t}(n)$ is the uniaxial tensile strength of the sandstone corresponding to the dry-wet cycle $n ; \sigma_{t 0}$ is the longitudinal wave velocity of the sandstone under the initial state; $a$ and $b$ are proportional constants; the specific values are shown in Table 8. The related coefficients of the two are both larger than 0.9861 , showing a good fitting effect.

The damage variable formula defined as tensile strength is shown as follows:

$$
D_{\sigma_{t}}(n)=1-\frac{\sigma_{t}(n)}{\sigma_{t 0}} .
$$

After (25) is substituted into (26), the following equation is obtained:

$$
D_{\sigma_{t}}(n)=1-\frac{\sigma_{t}(n)}{\sigma_{t 0}}=a \ln \left(n^{b}+1\right) .
$$

The fitting coefficients $a$ and $b$ under different working conditions are substituted into (27) to obtain the damage variables of two sizes $(h=25 \mathrm{~mm}, h=50 \mathrm{~mm}$ ) of sandstones under different dry-wet cycles, as shown in Figure 13. As seen from the figure, with the increase of dry-wet cycles, the damage variable of the specimen with $h=50 \mathrm{~mm}$ is larger than that with $h=25 \mathrm{~mm}$, and the damage variable value ranges within $0 \sim 1$. For the specimens of the same size under the same working condition, the damage variable of the saturated specimen is larger than that of the dry specimen, and the damage variable is increased as a logarithmic function with the increase of dry-wet cycles. When $h=50 \mathrm{~mm}$ and $n \geq 6$, through-wall cracks appear in the specimen, and its corresponding damage variable is 0.859 ; that is, when 
TABLE 8: Fitting coefficient of tensile strength of sandstones and dry-wet cycles in different conditions.

\begin{tabular}{|c|c|c|c|c|c|c|c|}
\hline Height (mm) & State & $n$ & Peak load $(\mathrm{kN})$ & Tensile strength (MPa) & $a$ & $b$ & Related coefficient $/ R^{2}$ \\
\hline \multirow{10}{*}{25} & \multirow{5}{*}{ Dry } & 0 & 11.761 & 5.990 & \multirow{5}{*}{0.146} & \multirow{5}{*}{0.953} & \multirow{5}{*}{0.9881} \\
\hline & & 1 & 10.508 & 5.352 & & & \\
\hline & & 3 & 9.447 & 4.811 & & & \\
\hline & & 6 & 8.781 & 4.472 & & & \\
\hline & & 10 & 7.643 & 3.892 & & & \\
\hline & \multirow{5}{*}{ Saturated } & 0 & 11.761 & 5.990 & \multirow{5}{*}{0.609} & \multirow{5}{*}{0.344} & \multirow{5}{*}{0.9927} \\
\hline & & 1 & 6.597 & 3.360 & & & \\
\hline & & 3 & 5.517 & 2.810 & & & \\
\hline & & 6 & 4.536 & 2.310 & & & \\
\hline & & 10 & 3.127 & 1.592 & & & \\
\hline \multirow{10}{*}{50} & \multirow{5}{*}{ Dry } & 0 & 23.181 & 5.903 & \multirow{5}{*}{0.354} & \multirow{5}{*}{0.553} & \multirow{5}{*}{0.9887} \\
\hline & & 1 & 17.122 & 4.360 & & & \\
\hline & & 3 & 14.962 & 3.810 & & & \\
\hline & & 6 & 12.998 & 3.310 & & & \\
\hline & & 10 & 10.180 & 2.592 & & & \\
\hline & \multirow{5}{*}{ Saturated } & 0 & 23.181 & 5.903 & \multirow{5}{*}{0.809} & \multirow{5}{*}{0.356} & \multirow{5}{*}{0.9861} \\
\hline & & 1 & 9.328 & 2.375 & & & \\
\hline & & 3 & 7.212 & 1.837 & & & \\
\hline & & 6 & 3.960 & 1.008 & & & \\
\hline & & 10 & 0.000 & 0.000 & & & \\
\hline
\end{tabular}

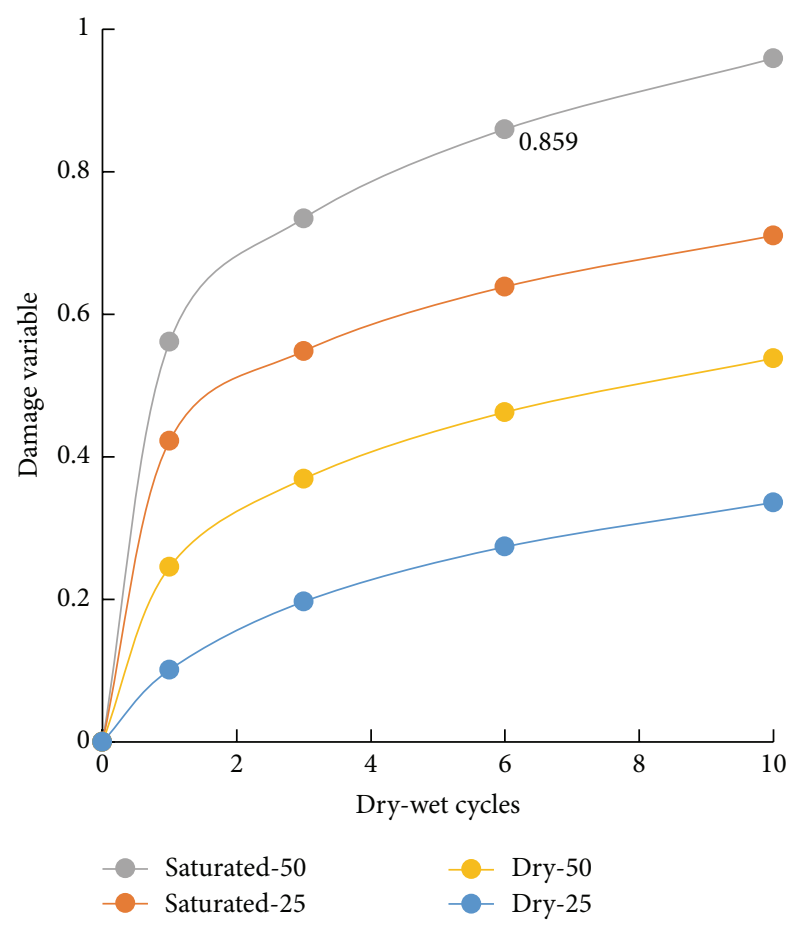

FIGURE 13: Relationship between damage variable of sandstones and dry-wet cycles.

the damage variable $D(n) \geq 0.859$ expressed by the uniaxial tensile strength of sandstone obtained in the splitting test, it loses its bearing capacity.

\section{Analysis on the Degradation Effect for Different Test Results of Sandstones under Dry-Wet Cycles}

The dry-wet cycle is a damage and degradation process emerging in the form of circulation. Thus, how to evaluate the degradation effect of cycles is a matter of concern. As previously mentioned, each immersion time of sandstones is the same, and so are the temperature and time of dehydration and drying. In the whole dry-wet cycle process, the water erosion effect is gradually enhanced. Therefore, the degradation increment arising from each cycle is the rational expression for measuring the dry-wet cycle effect. Through Sections 2 and 3 of the paper, the change rule of a series of micro/macrophysical damage factors of sandstone with the dry-wet cycle $n$ is obtained, and the curve fitting is conducted on it. If the relationship between the two is continuous, then through the derivation of dry-wet cycle $n$ in (8), (15), (20), and (28), respectively, the variation rate functions of damage and degradation of dry-wet cycles can be obtained:

$$
\begin{aligned}
& \dot{D}_{H}(n)=\frac{p q n^{q-1}}{n^{q}+1}, \\
& \dot{D}_{R}(n)=-2\left(\frac{e}{R_{0}}\right)^{2} n+\frac{2 e}{R_{0}}, \\
& \dot{D}_{P}(n)=-2\left(\frac{g}{V_{P 0}}\right)^{2} n+\frac{2 g}{V_{P 0}}, \\
& \dot{D}_{\sigma_{t}}(n)=\frac{a b n^{b-1}}{n^{b}+1} .
\end{aligned}
$$



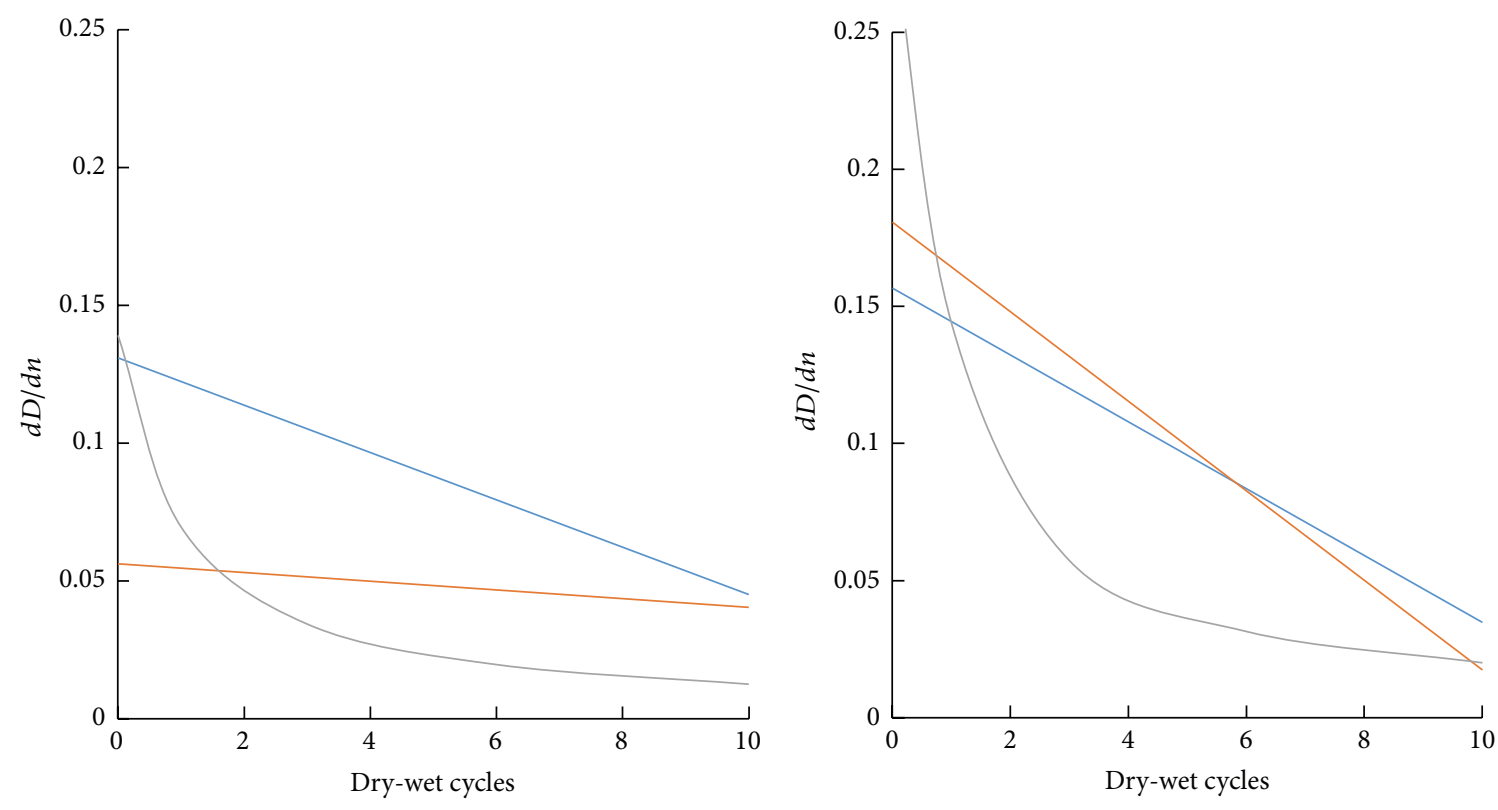

__ Velocity
Rebound value
Tensile strength

(a) Dry-25

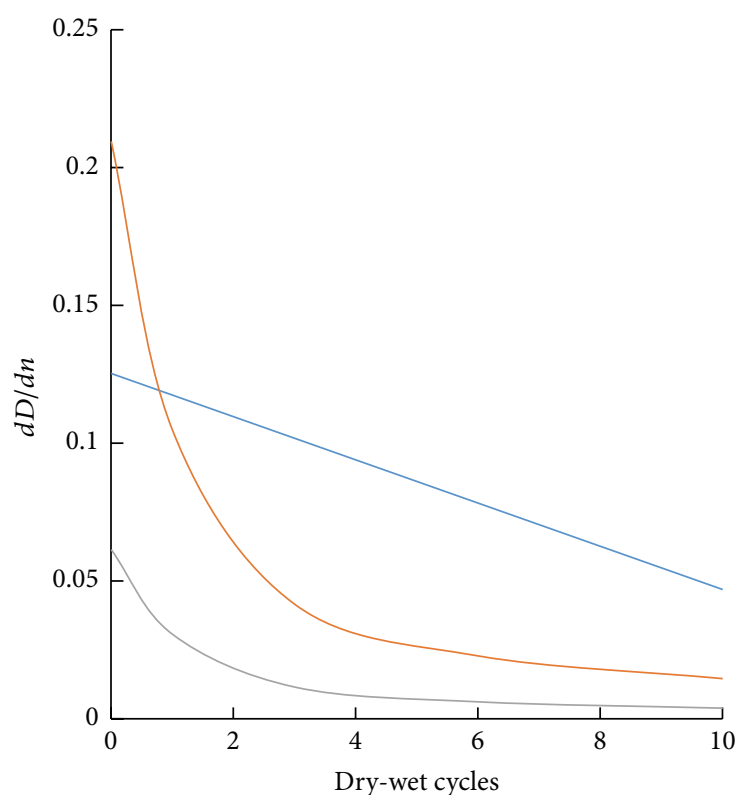

Velocity
Rebound value
Tensile strength

(b) Dry-50

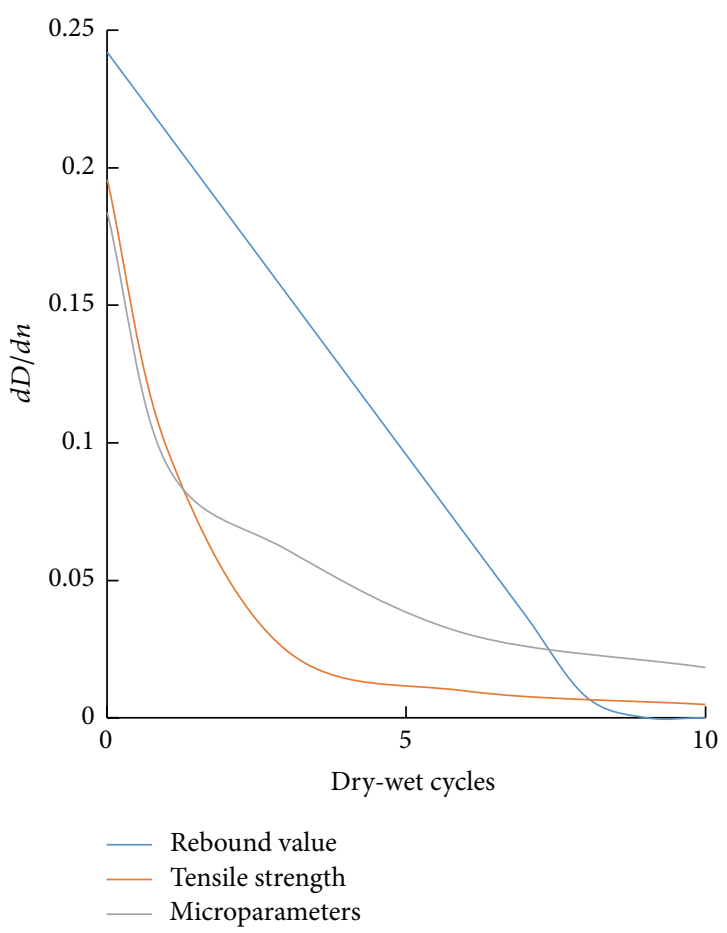

(d) Wet-50

FIGURE 14: Relationship between derived function of damage variable and dry-wet cycles.

The damage and degradation rates of different micro/ macroparameters varying with dry-wet cycles are drawn according to (29), as shown in Figure 14. As seen from the figure, the rate of each parameter of the sandstone with the thickness $h=50 \mathrm{~mm}$ varying with dry-wet cycle $n$ is larger than the specimen with $h=25 \mathrm{~mm}$, and the degradation effect is intense in the initial stage, which is larger than that in the later stage. For the sandstone under the dry condition, the variation rate of the rebound strength and longitudinal wave velocity of sandstone is linearly decreased 
with the dry-wet cycle $n$; the variation rate of tensile strength is logarithmically decreased, showing the steepest decreasing trend. For the sandstone under the saturated condition, the damage variation rate of its rebound strength is the largest and is linearly decreased with the dry-wet cycle $n$; tensile strength and microparameters are exponentially decreased, with a fast decreasing rate in the initial stage. When $n \geq 5$, the variation rate remained stable.

\section{Conclusion}

(1) Through the designed dry-wet cycle test, 0, 1, 3, 6, and 10 dry-wet cycles are conducted, respectively, on the sandstone to obtain the rebound strength, longitudinal wave velocity, tensile strength, and microparameters of two sizes ( $h=25 \mathrm{~mm}, h=50 \mathrm{~mm}$ ) of sandstones under dry and saturated conditions. With the increase of the dry-wet cycle $n$, the longitudinal wave velocity and the rebound strength of sandstones are linearly decreased; the uniaxial tensile strength of sandstone and the mean CT number of the cross section are logarithmically decreased with the increase of $n$.

(2) Under the same dry-wet cycles, the macro/micromechanical parameters of the "dry" sandstone are larger than those of the "saturated" one. When $h=50 \mathrm{~mm}$ and $n \geq 6$, through-wall cracks appear in the specimen. When damage variables of sandstone defined as mean CT number, longitudinal wave velocity, rebound strength, and tensile strength are, respectively, larger than $0.269,0.756,0.902$, and 0.859 , the sandstone loses its bearing capacity.

(3) The rate of the damage variable of the sandstone with the thickness $h=50 \mathrm{~mm}$ defined as macro/micromechanical parameters varying with the dry-wet cycle $n$ is larger than the specimen with $h=25 \mathrm{~mm}$, and the degradation effect is intense in the initial stage, which is larger than that in the later stage. For the sandstone under the dry condition, the variation rate of tensile strength is logarithmically decreased, showing the steepest decreasing trend. For the sandstone under the saturated condition, the damage variation rate of rebound strength is the largest; tensile strength and microparameters are exponentially decreased, with a fast decreasing rate in the initial stage. When $n \geq 5$, the variation rate remained stable.

\section{Competing Interests}

The authors declare that there is no conflict of interests regarding the publication of this paper.

\section{Authors' Contributions}

Zijuan Wang organized the experimental procedure and results and paper writing. Xinrong Liu, Yan Fu, Wen Yuan, and Luli Miao helped with the experimental procedure and analyzed the measured results.

\section{Acknowledgments}

This study is supported by the Fundamental Research Funds for the National Natural Science Foundation of China (Project no. 41372356) and the National Natural Science
Foundation of China (Project no. 51308567). The authors gratefully acknowledge this support.

\section{References}

[1] M. Duda and J. Renner, "The weakening effect of water on the brittle failure strength of sandstone," Geophysical Journal International, vol. 192, no. 3, pp. 1091-1108, 2013.

[2] A. B. Hawkins and B. J. McConnell, "Sensitivity of sandstone strength and deformability to changes in moisture content," Quarterly Journal of Engineering Geology, vol. 25, no. 2, pp. 115130, 1992.

[3] Z. A. Erguler and R. Ulusay, "Water-induced variations in mechanical properties of clay-bearing rocks," International Journal of Rock Mechanics and Mining Sciences, vol. 46, no. 2, pp. 355-370, 2009.

[4] D. T. Nicholson and F. H. Nicholson, "Physical deterioration of sedimentary rocks subjected to experimental freeze-thaw weathering," Earth Surface Processes and Landforms, vol. 25, no. 12, pp. 1295-1307, 2000.

[5] B. Vásárhelyi, "Some observations regarding the strength and deformability of sandstones in dry and saturated conditions," Bulletin of Engineering Geology and the Environment, vol. 62, no. 3, pp. 245-249, 2003.

[6] A. Prick, "Dilatometrical behaviour of porous calcareous rock samples subjected to freeze-thaw cycles," Catena, vol. 25, no. 14, pp. 7-20, 1995.

[7] X. Hu, H. Tang, C. Li, and R. Sun, "Stability of Huangtupo riverside slumping mass II\# under water level fluctuation of Three Gorges Reservoir," Journal of Earth Science, vol. 23, no. 3, pp. 326-334, 2012.

[8] T. T. Zhang, E. C. Yan, J. T. Cheng, and Y. Zheng, "Mechanism of reservoir water in the deformation of Hefeng landslide," Journal of Earth Science, vol. 21, no. 6, pp. 870-875, 2010.

[9] F.-W. Wang, Y.-M. Zhang, Z.-T. Huo, T. Matsumoto, and B.-L. Huang, "The July 14, 2003 Qianjiangping landslide, three gorges reservoir, China," Landslides, vol. 1, no. 2, pp. 157-162, 2004.

[10] W. Jian, Z. Wang, and K. Yin, "Mechanism of the Anlesi landslide in the three Gorges Reservoir, China," Engineering Geology, vol. 108, no. 1-2, pp. 86-95, 2009.

[11] S.-B. Bai, J. Wang, G.-N. Lü, P.-G. Zhou, S.-S. Hou, and S.-N. $\mathrm{Xu}$, "GIS-based logistic regression for landslide susceptibility mapping of the Zhongxian segment in the Three Gorges area, China," Geomorphology, vol. 115, no. 1-2, pp. 23-31, 2010.

[12] M. Xia, G. M. Ren, and X. L. Ma, "Deformation and mechanism of landslide influenced by the effects of reservoir water and rainfall, Three Gorges, China," Natural Hazards, vol. 68, no. 2, pp. 467-482, 2013.

[13] L. Peng, R. Q. Niu, B. Huang, X. L. Wu, Y. N. Zhao, and R. Q. Ye, "Landslide susceptibility mapping based on rough set theory and support vector machines: a case of the Three Gorges area, China," Geomorphology, vol. 204, pp. 287-301, 2014.

[14] F.-Z. Zhang and X.-P. Chen, "Influence of repeated drying and wetting cycles on mechanical behaviors of unsaturated soil," Chinese Journal of Geotechnical Engineering, vol. 32, no. 1, pp. 41-46, 2010.

[15] W.-M. Ye, Z.-Y. Qi, B. Chen et al., "Mechanism of cultivation soil degradation in rocky desertification areas under dry/wet cycles," Environmental Earth Sciences, vol. 64, no. 1, pp. 269-276, 2011. 
[16] K. Terzaghi, R. B. Peck, and G. Mesri, Soil Mechanics in Engineering Practice, John Wiley \& Sons, New York, NY, USA, 1996.

[17] H. Nowamooz and F. Masrouri, "Influence of suction cycles on the soil fabric of compacted swelling soil," Comptes RendusGeoscience, vol. 342, no. 12, pp. 901-910, 2010.

[18] F. S. Jeng, M. L. Lin, and T. H. Huang, "Wetting deterioration of soft sandstone-microscopic insights," in Proceedings of the ISRM International Symposium, International Society for Rock Mechanics, Melbourne, Australia, November 2000.

[19] M. L. Lin, F. S. Jeng, L. S. Tsai, and T. H. Huang, "Wetting weakening of tertiary sandstones-microscopic mechanism," Environmental Geology, vol. 48, no. 2, pp. 265-275, 2005.

[20] P. A. Hale and A. Shakoor, "A laboratory investigation of the effects of cyclic heating and cooling, wetting and drying, and freezing and thawing on the compressive strength of selected sandstones," Environmental \& Engineering Geoscience, vol. 9, no. 2, pp. 117-130, 2003.

[21] N. Reviron, T. Reuschlé, and J.-D. Bernard, “The brittle deformation regime of water-saturated siliceous sandstones," Geophysical Journal International, vol. 178, no. 3, pp. 1766-1778, 2009.

[22] C. O. Karacan and E. Okandan, "Adsorption and gas transport in coal microstructure: investigation and evaluation by quantitative X-ray CT imaging," Fuel, vol. 80, no. 4, pp. 509-520, 2001.

[23] K.-H. A. A. Wolf, F. van Bergen, R. Ephraim, and H. Pagnier, "Determination of the cleat angle distribution of the RECOPOL coal seams, using CT-scans and image analysis on drilling cuttings and coal blocks," International Journal of Coal Geology, vol. 73, no. 3-4, pp. 259-272, 2008.

[24] J. Eibl and B. Schmidt-Hurtienne, "Strain-rate-sensitive constitutive law for concrete," Journal of Engineering Mechanics, vol. 125, no. 12, pp. 1411-1420, 1999.

[25] S. K. Nath, S. Chakraborty, S. K. Singh, and N. Ganguly, "Velocity inversion in cross-hole seismic tomography by counterpropagation neural network, genetic algorithm and evolutionary programming techniques," Geophysical Journal International, vol. 138, no. 1, pp. 108-124, 1999.

[26] J. Mazars and G. Pyaudier-Cabot, "Continuum damage theory-application to concrete," Journal of Engineering Mechanics, vol. 115, no. 2, pp. 345-365, 1989.

[27] F. Pfeiffer and C. Glocker, Multibody Dynamics with Unilateral Contacts, Springer, 2000.

[28] J.-F. Dubé, G. Pijaudier-Cabot, and C. L. Borderie, "Rate dependent damage model for concrete in dynamics," Journal of Engineering Mechanics, vol. 122, no. 10, pp. 939-947, 1996.

[29] H. Guo, N. I. Aziz, and L. C. Schmidt, "Rock fracture-toughness determination by the Brazilian test," Engineering Geology, vol. 33, no. 3, pp. 177-188, 1993.

[30] S. K. Kourkoulis, C. F. Markides, and P. E. Chatzistergos, "The Brazilian disc under parabolically varying load: theoretical and experimental study of the displacement field," International Journal of Solids and Structures, vol. 49, no. 7-8, pp. 959-972, 2012.

[31] S. K. Kourkoulis, C. F. Markides, and P. E. Chatzistergos, "The standardized Brazilian disc test as a contact problem," International Journal of Rock Mechanics and Mining Sciences, vol. 57, pp. 132-141, 2013.

[32] A. Tavallali and A. Vervoort, "Effect of layer orientation on the failure of layered sandstone under Brazilian test conditions," International Journal of Rock Mechanics and Mining Sciences, vol. 47, no. 2, pp. 313-322, 2010.
[33] A. Tavallali and A. Vervoort, "Failure of layered sandstone under Brazilian test conditions: effect of micro-scale parameters on macro-scale behaviour," Rock Mechanics and Rock Engineering, vol. 43, no. 5, pp. 641-653, 2010.

[34] T. Zhang, E. Yan, J. Cheng, and Y. Zheng, "Mechanism of reservoir water in the deformation of Hefeng landslide," Journal of Earth Science, vol. 21, no. 6, pp. 870-875, 2010. 

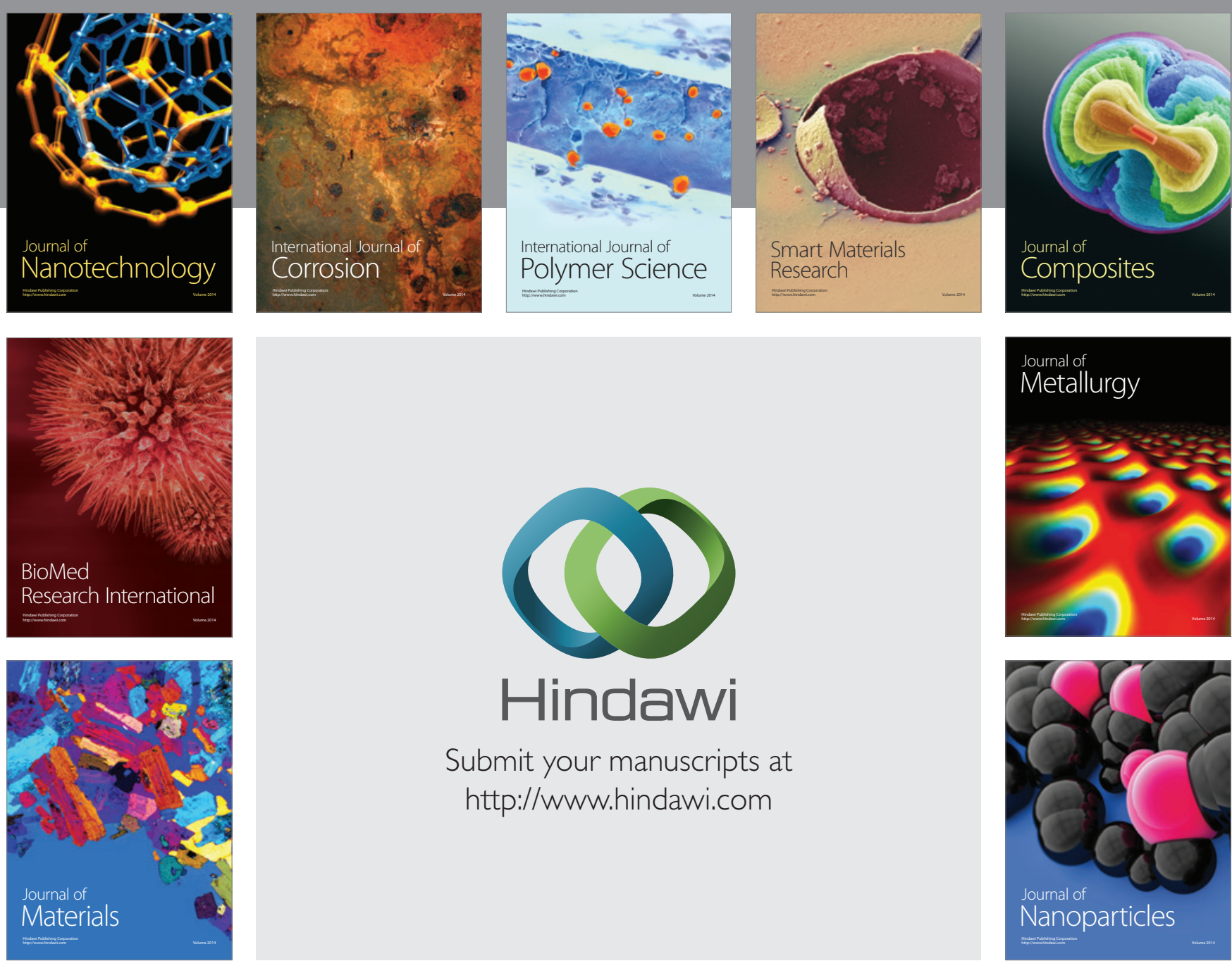

\section{Hindawi}

Submit your manuscripts at

http://www.hindawi.com

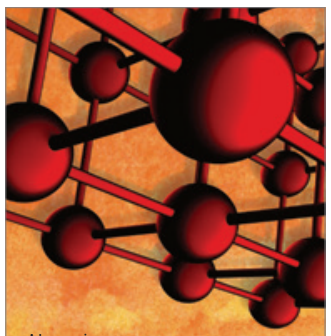

Materials Science and Engineering
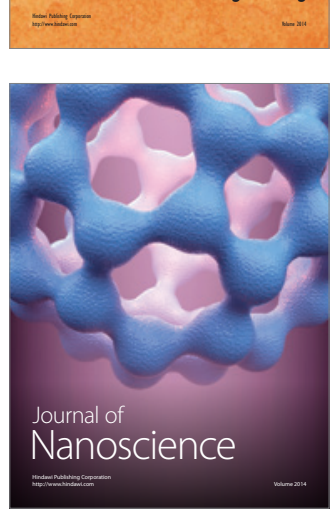
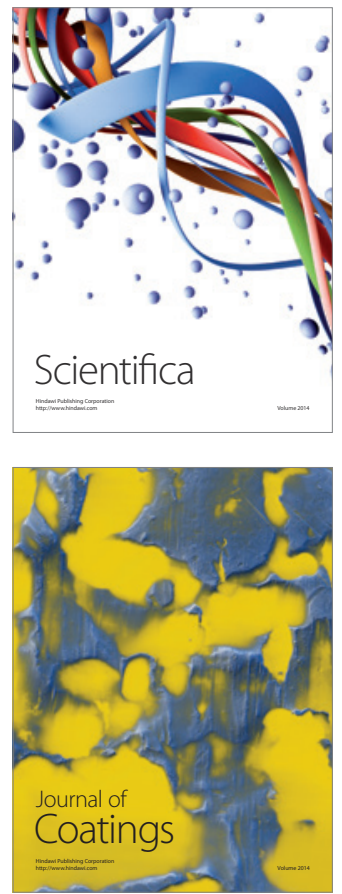
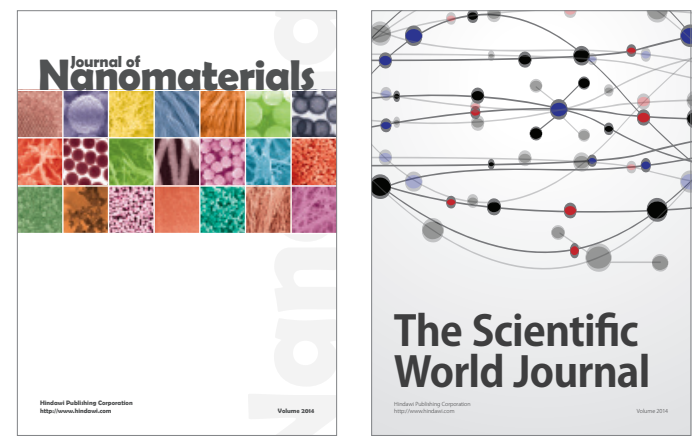

The Scientific World Journal
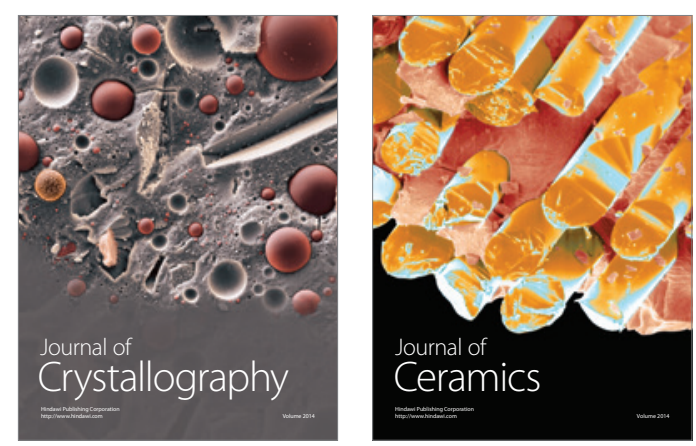
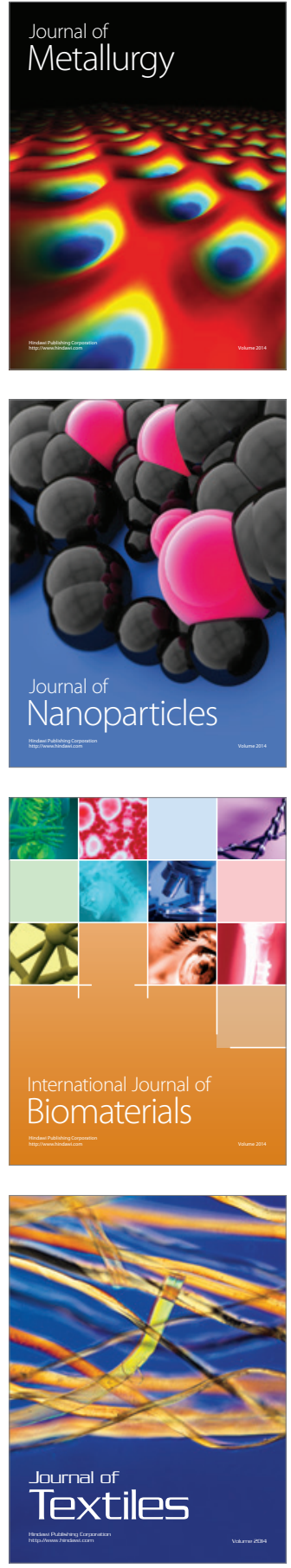